\title{
Weather Types and Rainfall over Senegal. Part I: Observational Analysis
}

\author{
VINCENT MORON \\ CEREGE, Université Aix-Marseille I, Aix en Provence, France, and International Research Institute for Climate and Society, The \\ Earth Institute at Columbia University, Palisades, New York, and Institut Universitaire de France, Paris, France \\ Andrew W. Robertson, M. Neil Ward, And Ousmane Ndiaye \\ International Research Institute for Climate and Society, The Earth Institute at Columbia University, Palisades, New York
}

(Manuscript received 24 July 2006, in final form 13 April 2007)

\begin{abstract}
A $k$-means cluster analysis is used to summarize unfiltered daily atmospheric variability at regional scale over the western Sahel and eastern tropical North Atlantic during the boreal summer season [JulySeptember (JAS)] 1961-98. The analysis employs zonal and meridional regional wind fields at 925, 700, and $200 \mathrm{hPa}$ from the European Centre for Medium-Range Weather Forecasts reanalyses. An eight-cluster solution is shown to yield an integrated view of the complex regional circulation variability, without the need for explicit time filtering. Five of the weather types identified characterize mostly typical phases of westward-moving wave disturbances, such as African easterly waves (AEWs), and persistent monsoon surges, while the three others describe mostly different stages of the seasonal cycle. Their temporal sequencing describes a systematic monsoonal evolution, together with considerable variability at subseasonal and interannual time scales.

Daily rainfall occurrence at 13 gauge stations in Senegal is found to be moderately well conditioned by the eight weather types, with positive rainfall anomalies usually associated with southerly wind anomalies at $925 \mathrm{hPa}$. Interannual variability of daily rainfall frequency is shown to depend substantially on the frequency of occurrence of weather types specific to the beginning and end of the JAS season, together with the number of persistent monsoon surges over the western Sahel. In contrast, year-to-year changes in the frequency of the weather types mostly associated with westward-moving waves such as AEWs are not found to influence seasonal frequency of occurrence of daily rainfall substantially.

The fraction of seasonal rainfall variability related to weather-type frequency is found to have a strong relationship with tropical Pacific sea surface temperatures (SSTs): an El Niño (La Niña) event tends to be associated with a higher (lower) frequency of dry weather types during early and late JAS season with enhanced trade winds over the western Sahel, together with lower (higher) prevalence of persistent monsoon surges. The component of seasonal rainfall variability not related to weather-type frequency is characterized by changes in rainfall probability within each weather type, especially those occurring in the core of the JAS season; it exhibits a larger decadal component that is associated with an SST pattern previously identified with recent observed trends in Sahel rainfall.
\end{abstract}

\section{Introduction}

Many previous studies have investigated the interannual and longer-term variability of seasonal mean rainfall in the Sahel region in general (i.e., Nicholson 1979; Fontaine and Bigot 1993; Moron 1994; Rowell et al. 1995; Ward 1998) as well as for Senegal in particular (Camberlin and Diop 1999, 2003). Folland et al. (1986) demonstrated the association between the changes in sea surface temperatures (SST) and Sahelian seasonal

Corresponding author address: Vincent Moron, Université d'Aix-Marseille I and CEREGE, UMR 6635 CNRS, Europôle Méditerranéen de l'Arbois, BP 80, 13545 Aix en Provence, France.

E-mail: moron@cerege.fr

DOI: 10.1175/2007JCLI1601.1

(C) 2008 American Meteorological Society mean rainfall variability. Several studies (Lamb 1978; Hastenrath 1984, 1990; Rowell et al. 1995; Ward 1998) identified a strong relationship between the interhemispheric gradient of SST and multidecadal variability of Sahelian rainfall. The relationships between SST and Sahelian rainfall at interannual time scales are more complex and less stable (Janicot et al. 1996; Ward 1998). Wetter (drier) conditions in the Sahel are usually associated with cold (warm) El Niño-Southern Oscillation (ENSO) events, anomalously cold (warm) SST anomalies (SSTAs) over the equatorial and southern Atlantic and the western Indian Ocean, and anomalously warm (cold) SSTAs over the northern tropical Atlantic. These empirical relationships have been largely confirmed by atmospheric general circulation 
model (AGCM) experiments with historical SSTs prescribed (Rowell et al. 1995; Moron et al. 1998, 2004; Giannini et al. 2003; Paeth and Friederichs 2004). Such experiments have been highly successful at simulating the multidecadal variability of Sahelian rainfall (Giannini et al. 2003), though relatively few models are successful at interannual time scales, especially during the post-1967 dry period (Sperber and Palmer 1996; Moron et al. 2003; Moron 2005).

The above studies have focused almost exclusively on seasonal mean rainfall, while very little attention has been given to the interannual variability of subseasonal quantities such as the number of rainy days, length of dry/wet spells, etc. Rainfall over West Africa during the summer monsoon is mainly associated with mesoscale convective systems, especially over the Sahel (D'Amato and Lebel 1998; Laurent et al. 1998; Lebel et al. 2003). These are often, but not always, embedded within African easterly waves (AEWs; Burpee 1972) that arise from barotropic/baroclinic instability of the middle-troposphere African easterly jet (AEJ) extended west-east over most of the Sahel near $15^{\circ} \mathrm{N}$. Nevertheless, the link between convection (and rainfall) and easterly waves is far from linear and remains controversial (Thorncroft and Rowell 1998; Diedhiou et al. 1998, 1999, 2001; Grist 2002; Gu and Adler 2004; Gu et al. 2004; Lavaysse et al. 2006). Fink and Reiner (2003) argue that the strength of coupling between AEWs and mesoscale convective systems increases toward the West African coast, consistent with the observed westward growth of wave amplitude. Taleb and Druyan (2003) indicated that $>70 \%$ of the seasonal rainfall at Dakar, Senegal, is accounted for by 3-9-day variability of meridional wind at $700 \mathrm{hPa}$, consistent with 3-5- and 6-9-day AEW regimes (Diedhiou et al. 1998, $1999,2001)$. AEWs are not the only subseasonal modulator of the rainfall. Janicot and Sultan (2001) identified a westward-propagating quasi-periodic signal with a period of about 15-40 days. This signal is associated with the meridional shift of the intertropical convergence zone (ITCZ) (Sultan and Janicot 2000) and the surges of the West African monsoon (Louvet et al. 2003). Even slower subseasonal components have also been identified (Sultan et al. 2003; Matthews 2004). In summary, the subseasonal variability of rainfall in Sahel is composed of the interactions between interrelated processes with various time and space scales (Sultan et al. 2003; Druyan et al. 2006). It is little understood how these subseasonal processes are influenced by SST forcing.

Most of the studies cited above used bandpassfiltered time series to analyze subseasonal variability and its relationship with local-to-regional rainfall within a specified frequency range. A different approach is pursued here, based on an objective clustering method ( $k$-means) that is used to partition unfiltered daily atmospheric variability into different weather types. In the extratropics, such a clustering scheme is commonly used to define so-called weather regimes (Mo and Ghil 1988; Molteni et al. 1990). These weather regimes are usually interpreted as preferred states of a nonlinear dynamical system with a chaotic attractor (Ghil and Robertson 2002). They are characterized by persistent large-scale flow patterns that appear repeatedly at fixed geographical locations and organize the behavior of synoptic-scale motions during several days or weeks (Michelangeli et al. 1995; Robertson and Ghil 1999). As the name implies, weather regimes affect local weather. The "episodic" approach to circulation variability, via cluster analysis, has been shown to be complementary to an "oscillatory" approach, via spectral analysis, both conceptually (Ghil and Robertson 2002) and in practice, the latter using for example a $k$-means analysis of Pacific-South American circulation variability (Robertson and Mechoso 2003). Even in the case of a propagating wave, a cluster analysis may provide a useful coarse-grained discretization of the wave, with a "resolution" provided by the number of clusters chosen.

The goals of the present study are (i) to propose an objective partitioning of the regional-scale atmospheric circulation variability over the western Sahel and eastern tropical North Atlantic $\left(5^{\circ}-25^{\circ} \mathrm{N}, 0^{\circ}-30^{\circ} \mathrm{W}\right)$, considering all time scales; and (ii) to analyze how these "weather types" affect local rainfall in Senegal. The use of these weather types in downscaling studies is illustrated in the second part of this study (Moron et al. 2008, hereafter Part II). Section 2 describes the daily station rainfall dataset together with the reanalysis atmospheric circulation data. The weather types are presented in section 3. A summary and discussion are presented in section 4 .

\section{Datasets}

\section{a. Rainfall}

The study uses a 13-station network (Fig. 1a) of daily rainfall observations over Senegal as in Moron et al. $(2006,2007)$. This network includes the 10 main synoptic stations of the country and 3 nonsynoptic stations (i.e., Diouloulou, Kounghel, and Goudiry). The data used in this study cover the period from 1 July 1961 to 30 September 1998 (JAS hereafter). The lack of available daily rainfall data after 1998 prevented the use of a longer period, but the analyzed time series includes parts of the predominantly wet and dry periods before and after 1968 (i.e., Nicholson 1979; Moron 1994). The dataset is complete although some of the data are 
(a) location map

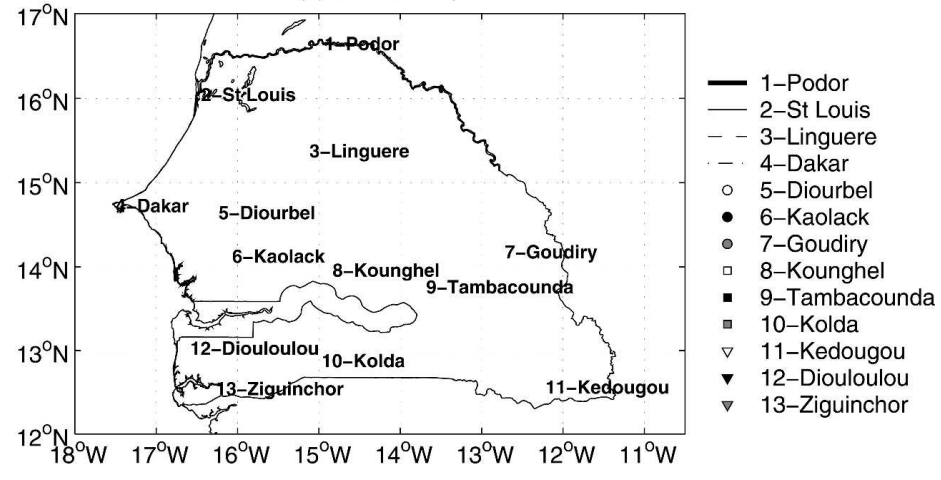

(b) mean frequency of wet days (i.e. receiving more than $1 \mathrm{~mm}$ )

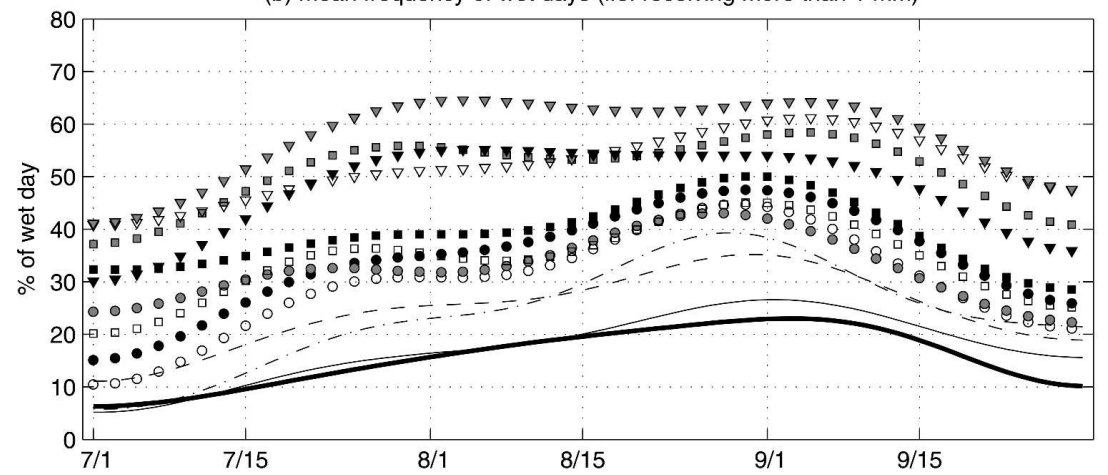

(c) mean rain amounts on wet days

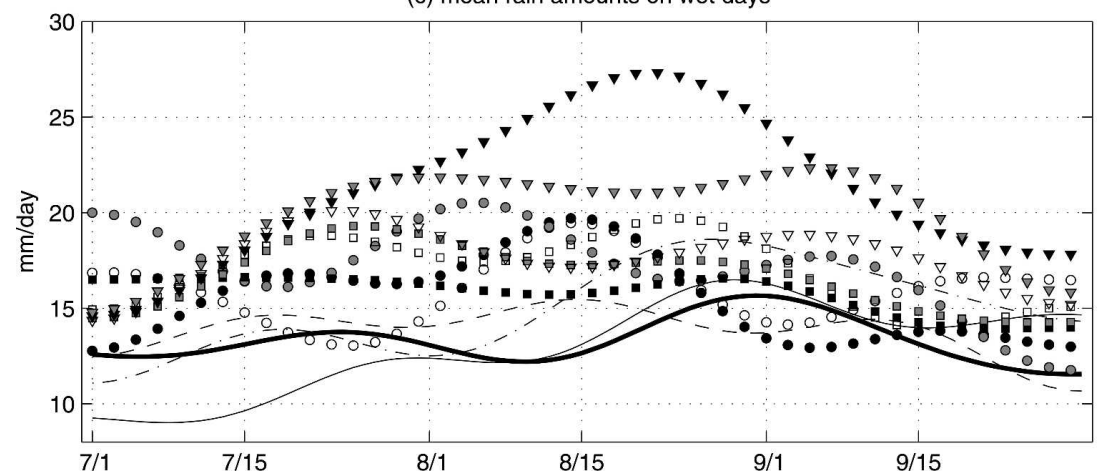

FIG. 1. (a) Map location of the 13 stations, (b) mean daily rainfall frequency ( $\%$ of wet days receiving more than $1 \mathrm{~mm}$ of rainfall) at each station, and (c) mean daily rainfall amounts ( $\mathrm{mm} \mathrm{day}^{-1}$ in wet days) for the 13 stations of the observed network. The curves represent a smoothed seasonal cycle (low-pass recursive filter retaining only frequencies lower than $1 / 30$ cycles per day). The number refers to each station on the location map in (a) (1: Podor, 2: St Louis, 3: Linguere, 4: Dakar-Yoff, 5: Diourbel, 6: Kaolack, 7: Goudiry, 8: Kounghel, 9: Tambacounda, 10: Kolda, 11: Kedougou, 12: Diouloulou, and 13: Ziguinchor).

doubtful. In particular, the three nonsynoptic stations have significantly less wet days between 0 and $1 \mathrm{~mm}$ than the neighboring stations. The possible related bias in the frequency of occurrence of rainy days is eliminated by using a threshold of $1 \mathrm{~mm}$ for defining wet days (Moron et al. 2007).

Senegal is a flat Sahelian country neighboring the tropical North Atlantic. As for the entire Sahel, the rainy season grows longer southward (Figs. 1b,c), associated with the latitudinal migration of the ITCZ. Daily rainfall occurrence frequency (days receiving $>1 \mathrm{~mm}$ ) usually peaks between 25 August and 5 September, north of $13.5^{\circ} \mathrm{N}$ (Fig. 1b). The seasonal cycle is flatter for the four southernmost stations (i.e., Ziguinchor, Di- 
ouloulou, Kolda, and Kedougou) with almost no difference between 20 July and 10 September (Fig. 1b). The amplitude of the seasonal cycle is small for the mean daily rain amount on wet days with a peak around the end of August in the northern two-thirds of the country (Fig. 1c); it is also small in southern Senegal (i.e., higher rainfall amount from 20 July to 10 September) associated with higher rainfall rates than in the north-central part of the country (Fig. 1c).

\section{b. ERA-40}

The 40-yr European Centre for Medium-Range Weather Forecasts (ECMWF) Re-Analysis project (ERA-40; Simmons and Gibson 2000) data are used to describe variability of the atmospheric circulation. The data are available on a $2.5^{\circ} \times 2.5^{\circ}$ grid every $6 \mathrm{~h}$ from 1 September 1957 to 31 August 2002. The daily mean of the zonal and meridional components of the winds at 925,700 , and $200 \mathrm{hPa}$ over the area $\left(5^{\circ}-25^{\circ} \mathrm{N}, 30^{\circ} \mathrm{W}-0^{\circ}\right)$ from 1 July 1961 to 30 September 1998 are used in this study. Figure 2 displays the mean JAS climatology of the wind at 200 (Fig. 2a), 700 (Fig. 2b), and $925 \mathrm{hPa}$ (Fig. 2c), as well as the mean seasonal cycle of these winds over Senegal (Figs. 2d-f). The low-level winds exhibit the classical low-level monsoon flow with a convergence near $7^{\circ} \mathrm{N}$ over the tropical Atlantic and shifted northward to near $20^{\circ} \mathrm{N}$ at $0^{\circ} \mathrm{E}$, associated with the thermal low centered over the Sahara (Fig. 2c). The predominantly westerly flow over Senegal is strongest during late July and is replaced by northeasterlies in September (Fig. 2f). The main feature of the middle troposphere is the AEJ with axis near $15^{\circ} \mathrm{N}$ (Fig. 2b); it is only weakly modulated by the seasonal cycle during the period in ERA-40, with a slight weakening around late July and in late September (Fig. 2e). The tropical easterly jet (TEJ) dominates the upper troposphere, with Senegal near its northern margin (Fig. 2a). Its axis is located south of the AEJ, and its seasonal cycle matches that at lower levels peaking around the end of July (Fig. 2d), that is, before the rainy peak of the JAS season (Figs. 1b,c). The mean upper-level winds become weak westerlies in late September (Fig. 2d). Note that the ERA-40 fields were linearly interpolated from the original $2.5^{\circ} \times 2.5^{\circ}$ grid onto a T42 Gaussian grid for the following analyses, to facilitate the use of the ECHAM4.5 GCM simulations in Part II.

\section{Weather types}

\section{a. Definition of the number of weather types}

A standard $k$-means cluster analysis is applied to the seven leading unstandardized, that is, their temporal variance being proportional to their eigenvalues, prin- cipal component (PC) of both zonal and meridional components of the ERA-40 daily winds, previously normalized to zero mean and unit variance at each grid point, accounting for $52 \%$ of their total daily variance. Considering more PCs to retain a larger fraction of the variance yields very similar weather types but slows the computations used in Part II. $K$-means is an iterative clustering procedure (Diday and Simon 1976) that consists in partitioning the data into $k$ clusters so as to minimize the sum of variance within-cluster. The first step concerns choosing the appropriate number of clusters. This is determined using two statistical scores: the classifiability index (Michelangeli et al. 1995; Plaut and Simonnet 2001) and the information criterion (Santos et al. 2005).

The classifiability index (CI) measures the dependence of a partition into $k$ clusters on the initial seeds. Here 100 partitions are performed in the subspace defined by the leading seven PCs, for $k$ varying from 2 to 10 using randomly chosen initial seeds. The similarity between two partitions is calculated in terms of the anomaly correlation coefficient between the cluster centroids in the PC space (Michelangeli et al. 1995). For any cluster $i$ of partition $\mathbf{P}$, the cluster of partition $\mathbf{Q}$ with maximum anomaly correlation coefficient defines the cluster $j$ that most resembles it. The minimum value of this distribution defines the CI for cluster $i$ of partition $\mathbf{P}$, that is, the worst-fitting counterpart. When two partitions are identical, $\mathrm{CI}=1$ for all clusters. $\mathrm{CI}$ is computed for 100 partitions and averaged to give a CI for a number $k$ of clusters. The best partition maximizes the CI averaged across the $k$ clusters.

For reference, we define a first-order Markov process having the same covariance at lag 0 and 1 as the unstandardized leading seven PCs of wind data, following Michelangeli et al. (1995) and Plaut and Simonnet (2001). This seven-dimensional noise model is used to generate 100 samples of the same length as the wind dataset and CI is calculated for each of them. The CI is shown in Fig. 3a as a function of the number of clusters, together with the two-sided $90 \%$ confidence bounds. The CI drops to a minimum at $k=5$ and then increases to a plateau above 0.70 for $k=8$ to 10 ; it emerges from the noise for $k=3$, then from $k=7$. The fact that CI is quite stable from $k=7$ is further discussed below. The classifiability of any dataset is closely related to the reproducibility of clusters (Michelangeli et al. 1995).

While the CI yields information on the partition of wind data, it says nothing about the degree of discrimination of Senegal's daily rainfall on these clusters. There are various ways to estimate the discrimination of rainfall by cluster. The information criterion (IC) suggested by Santos et al. (2005; Fig. 3b) is used for that purpose: 
(a) mean wind at $200 \mathrm{hPa}$

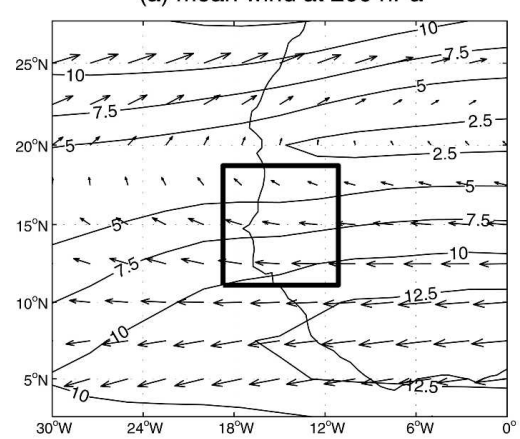

(b) mean wind at $700 \mathrm{hPa}$

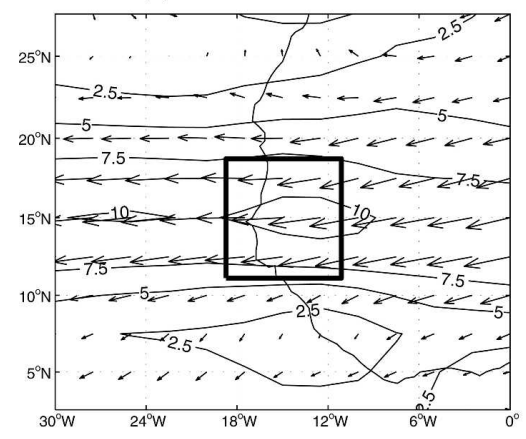

(c) mean wind at $925 \mathrm{hPa}$

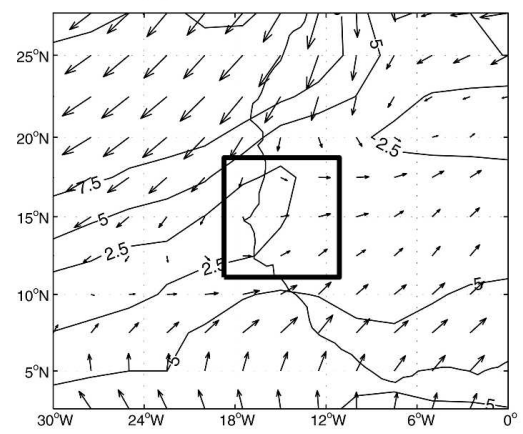

(d) mean $\mathrm{U}$ and $\mathrm{V}$ at $200 \mathrm{hPa}$ over Senegal

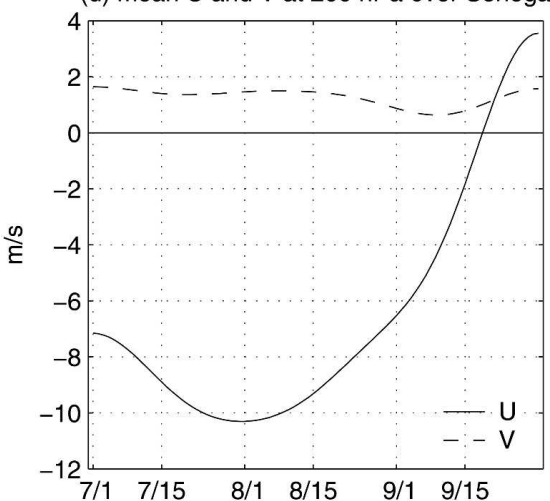

(e) mean $\mathrm{U}$ and $\mathrm{V}$ at $700 \mathrm{hPa}$ over Senegal
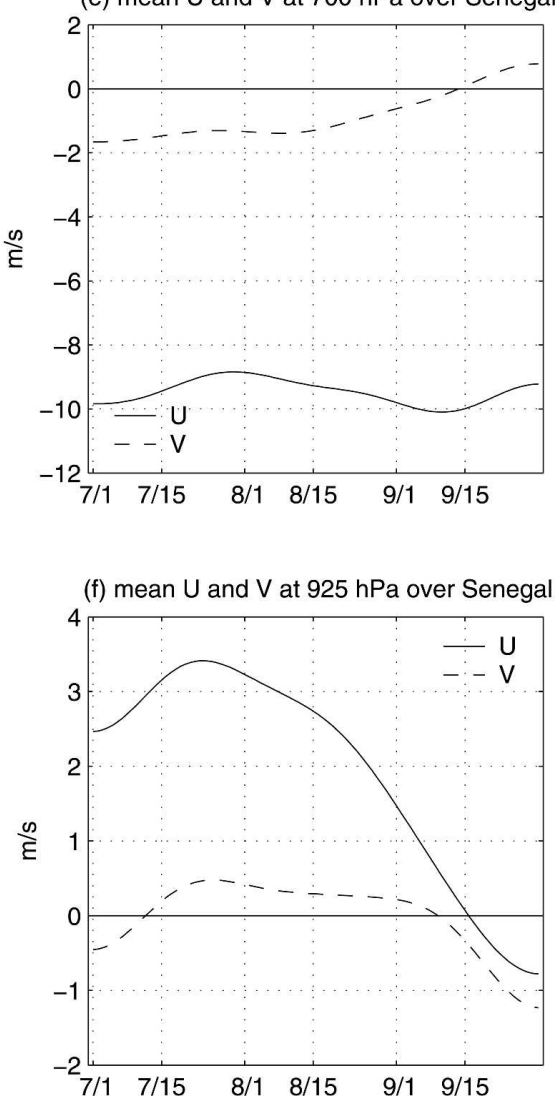

FIG. 2. Mean ERA-40 wind (vectors) and speed (contour every $2.5 \mathrm{~m} \mathrm{~s}^{-1}$ ) in JAS 1961-98 at (a) 200, (b) 700, and (c) $925 \mathrm{hPa}$. The right column displays the seasonal cycle (=mean of daily values filtered by a low-pass recursive filter retaining only frequencies lower than $1 / 30$ cycles per day) of the (d) 200-, (e) 700-, and (f) $925-\mathrm{hPa}$ winds averaged over the nine grid points covering Senegal (i.e., $12.5^{\circ}-17.5^{\circ} \mathrm{N}, 12.5^{\circ}-17.5^{\circ} \mathrm{W}$ ) delineated as a black box in (a)-(c).

$$
\mathrm{IC}=\sum_{i=1}^{k}\left|n_{i, r}-\left(p_{r} \times n_{i}\right)\right| .
$$

Here $n_{i, r}$ is the number of days in cluster $i$ that receive a rainfall amount greater than $r, p_{r}$ is the probability of such rainy days in the whole population, $n_{i}$ is the number of days in cluster $i$, and $k$ is the total number of clusters. Figure $3 \mathrm{~b}$ shows IC as a function of $k$ for each station, together with the country average, using a threshold $r=1 \mathrm{~mm}$. The information criterion IC ex- 

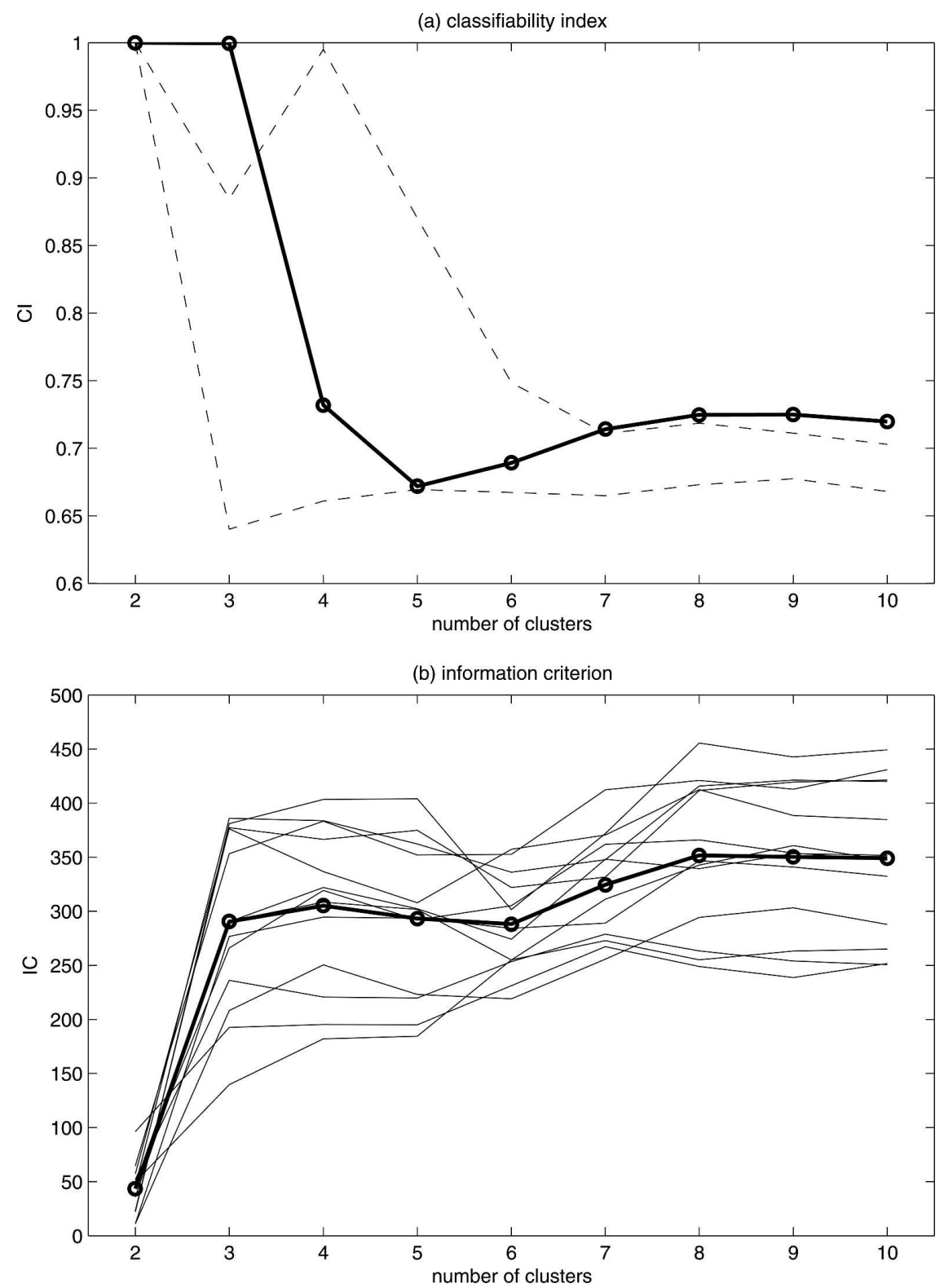

FIG. 3. (a) CI (Michelangeli et al. 1995) for 2-10 clusters (bold line with circle) defined with $k$-means on the seven leading PCs of zonal and meridional components of ERA-40 winds at 925, 700, and $200 \mathrm{hPa}$. The dashed line gives the CI two-sided $90 \%$ confidence interval extracted from 100 simulations with red noise having the same covariance at lag 0 and 1 as the seven leading PCs of wind data. (b) Information criterion (Santos et al. 2005) computed on daily rainfall with a threshold of $1 \mathrm{~mm}$. Each station is displayed as a thin line while the bold line with dots represents the country average. The $2-10$ clusters are defined with $k$-means on the seven leading PCs of zonal and meridional components of ERA-40 winds at 925, 700, and $200 \mathrm{hPa}$.

hibits a large jump from 2 to 3 clusters, and a second smaller increase from 6 to 8 clusters. The curve is then almost flat from 8 to 10 clusters. We choose 8 clusters as a compromise between adequate discrimination of local rainfall, CI, and the physical interpretation of the atmospheric circulation patterns.

\section{b. Temporal sequence of weather types}

The occurrence frequency of each weather type (WT) varies on interannual time scales but also within each season. The mean seasonal cycle of each WT, the probabilities of transitions between them, and the spell- 

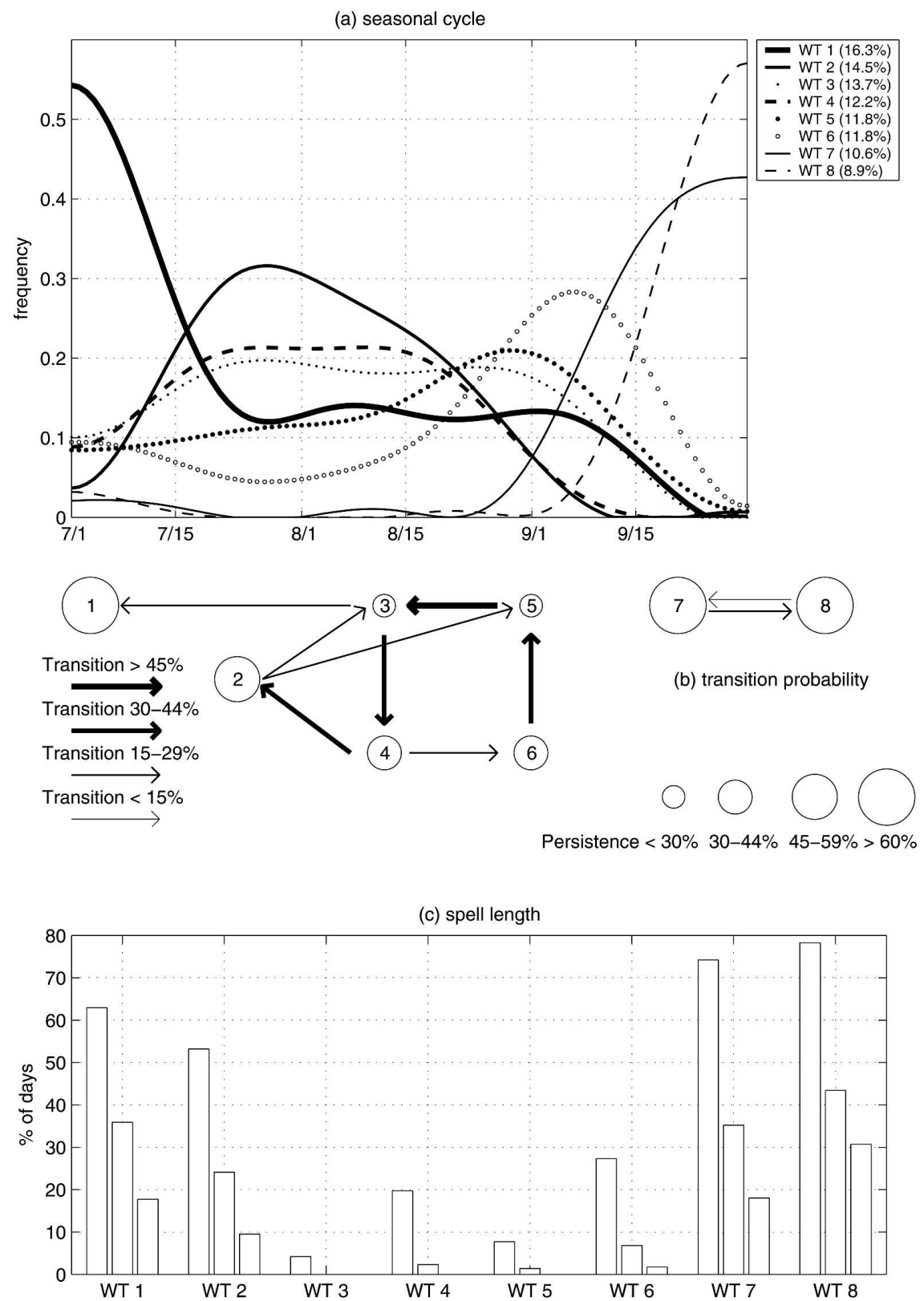

FIG. 4. (a) Seasonal variation of the WTs. The seasonal cycle (= mean of daily value) is smoothed by a low-pass filter retaining periods lower than $1 / 30$ cycles per day. (b) Probability transition between the weather types. The arrows indicate the transition that occurs more likely than chance at the one-sided 99\% level (Vautard et al. 1990), and the circles around the weather types are proportional to the one-day persistence. (c) Percentage of days of each type included in homogenous spells lasting at least 3,5, and 7 days.

length distributions are illustrated in Fig. 4. The transition probabilities are tested using a Monte Carlo test for transition matrix based on Markov chains (Vautard et al. 1990). We generate 38 random time sequences of numbers from 1 to 8 . Each sequence has a length of 92 time units and the total frequency of occurrence of each cluster is made to match the observed one. We then compute the transition matrix from this 38 time units $\times$
92 days matrix and the process is repeated 10000 times. Observed transition probabilities exceeding the 99th percentile of their noise counterparts are taken to be statistically significant at the one-sided 99\% level.

The occurrence of WT 1, and especially that of WT 7 and WT 8 , are strongly modulated by the seasonal cycle: WT 1 is prevalent before about 15 July, and WTs 7 and 8 after about 15 September. WT 1 also occurs 
during the core of the JAS season in persistent spells (e.g., 1968, 1972, 1977, 1978, 1981, 1986, and 1987; not shown). The WTs 2-6 are most prevalent from about 10 July to about 20 September but rarely persist for more than 5 days, except perhaps for WT 2 (e.g., July 1975, July 1981, and August 1994; not shown). The transitions amongst the five WTs reveal preferred circuits: $2 \rightarrow 3$ $\rightarrow 4 \rightarrow 2,3 \rightarrow 4 \rightarrow 6 \rightarrow 5 \rightarrow 3$ and $2 \rightarrow 5 \rightarrow 3 \rightarrow 4 \rightarrow$ 2 (Fig. 4b), suggesting that these WTs may be associated with westward-moving wave disturbances as AEWs. Inspection of the daily WT sequences for each year (not shown) indicates that these circuits typically last 3-9 days.

\section{c. Atmospheric patterns}

Composite maps of daily wind anomalies for the eight weather types at 925 and $700 \mathrm{hPa}$ are presented in Figs. 5-8. The wind anomalies at $200 \mathrm{hPa}$ are not shown since they mostly reflect the seasonal cycle of each cluster. These figures are organized following the mean seasonal evolution, with the early-season WT 1 shown in Fig. 5, the WTs of the core JAS season displayed together in Figs. 6 and 7, and the late-season WTs 7 and 8 shown in Fig. 8. The composites are plotted as standardized anomalies relative to the long-term JulySeptember mean. Anomalies of divergence exceeding 0.25 standard deviations are shaded in Figs. 5-8, with standardized anomalies greater than 0.25 (light) and less than -0.25 (dark). Note that the maps cover a larger area than the window used in the clustering. A Student's $t$ test was applied to the wind anomalies in Figs. 5-8, with the number of effective degrees of freedom taken as the total number of days included in each composite divided by 10 , to account for persistence. All of the main circulation features tested are significant at the $99 \%$ confidence level using a two-sided test (not shown).

With respect to the JAS mean, WT 1 is characterized by an anomalous anticyclone at $700 \mathrm{hPa}$, centered to the west of Senegal (Fig. 5a), with strong surface northerly anomalies to the north, and an anomalous cyclonic center located near $20^{\circ} \mathrm{N}, 5^{\circ} \mathrm{W}$ at $925 \mathrm{hPa}$ (Fig. 5b). A region of anomalous convergence is located at $925 \mathrm{hPa}$ over northern Senegal, with anomalous divergence above it at $700 \mathrm{hPa}$. A larger window indicates that this weather type is not related to particular extratropical features (not shown). These features largely reflect mean conditions during early July when WT 1 is prevalent, prior to the core monsoon season. However, similar composites result if the season is split into two, to consider the early (pre-July 16) and core parts of the season separately (not shown). Thus, WT 1 may be

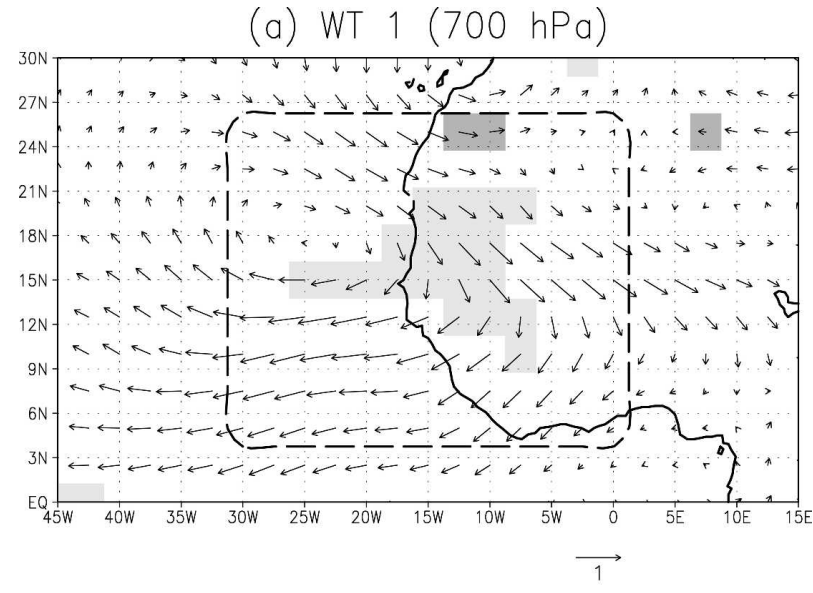

(b) WT $1(925 \mathrm{hPa})$

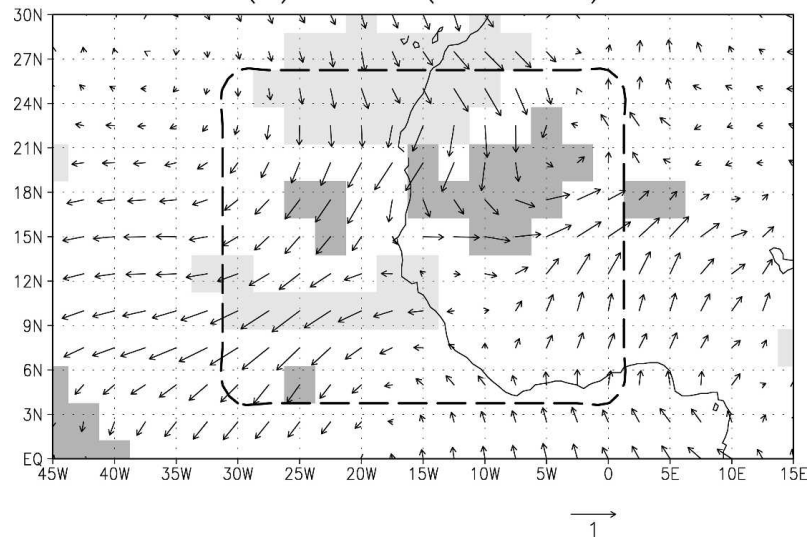

FIG. 5. Composite maps of (a) 700- and (b) 925-hPa anomaly winds of weather type 1 . The raw data from July 1961 to 30 Sep 1998 are normalized to zero mean and unit variance before the computation of the composite. Shading indicates composite anomalies of divergence greater than 0.25 (light) and less than -0.25 (dark). Divergence $(D)$ is computed from the raw zonal $(u)$ and meridional $(v)$ winds in Cartesian coordinates $[D=(d u / d x)+$ $(d v / d y)]$ and then standardized to zero mean and unit variance. Positive (negative) values indicate anomalous divergence (convergence). The weather types are computed from wind data in $2.5^{\circ}-$ $27.5^{\circ} \mathrm{N}, 30^{\circ} \mathrm{W}-0^{\circ}$ delineated by a dashed black box.

associated with "breaks" during the core monsoon season, with circulation features typical of early July.

At 925 (Fig. 6) and $700 \mathrm{hPa}$ (Fig. 7), weather types 2-6 all exhibit wavy patterns whose spatial structures are broadly consistent with westward-moving easterly wave disturbances (Burpee 1972) when ordered according to the temporal sequences identified in Fig. 4b (Diedhiou et al. 1998, 1999; Grist 2002). WT 3 is almost a mirror image of WT 6 over the region used to define the clusters. In terms of horizontal structure at $700 \mathrm{hPa}$, the zonal wavelength, horizontal phase tilts, and meridional extent all exhibit the hallmarks of AEWs identified at $15^{\circ} \mathrm{N}$ in a previous study of ERA-15 data by 
(a) WT $2(925 \mathrm{hPa})$

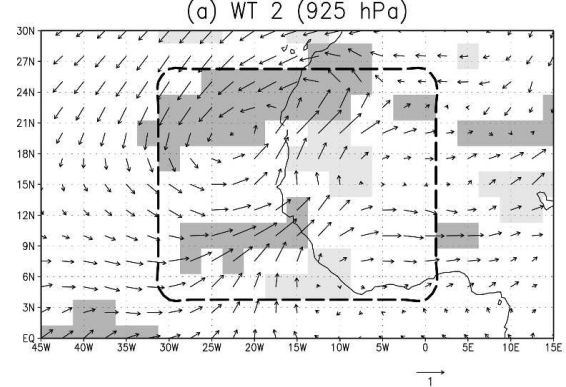

(b) WT $3(925 \mathrm{hPa})$

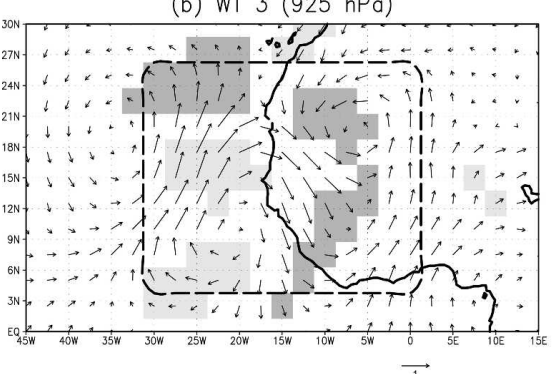

(d) WT $5(925 \mathrm{hPa})$

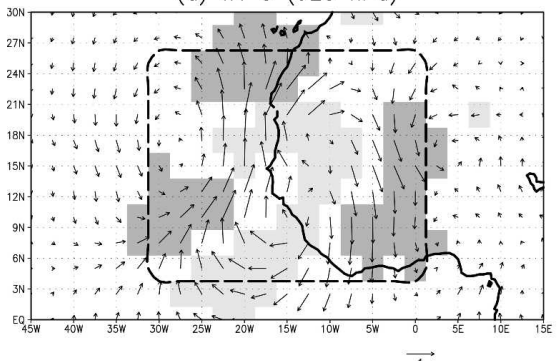

(c) WT $4(925 \mathrm{hPa})$

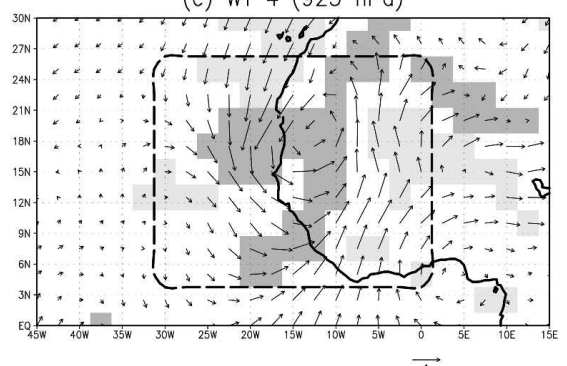

(e) WT $6(925 \mathrm{hPa})$

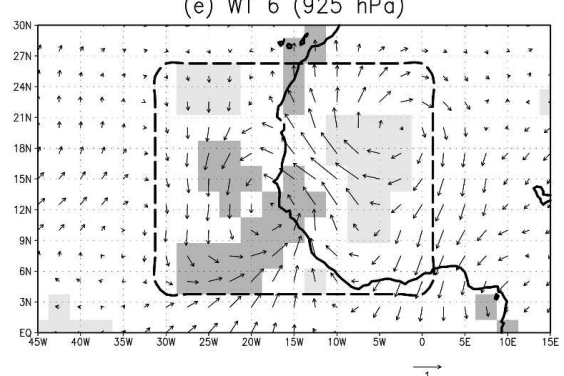

FIG. 6. Composite maps of 925-hPa anomaly winds for (a) WT 2, (b) WT 3, (c) WT 4, (d), WT 5, and (e) WT 6. Shading indicates composite anomalies of divergence greater than 0.25 (light) and less than -0.25 (dark). Details as in Fig. 5 .

Kiladis et al. (2006); this is compatible with the location of the WT troughs and ridges in Fig. 7, whose centers at $700 \mathrm{hPa}$ are located close to the latitude of the AEJ along $15^{\circ} \mathrm{N}$. The anomalous convergence at $700 \mathrm{hPa}$ tends to be in phase with anomalous southerly winds, to the east of the trough axis. This is also consistent with AEWs identified at $15^{\circ} \mathrm{N}$ by Kiladis et al. (2006), while they found a different configuration at $10^{\circ} \mathrm{N}$. Although they exhibit these AEW characteristics, the patterns of WTs 2 and 4 are also consistent with slower intraseasonal modes, such as monsoon surges (Janicot and Sul$\tan$ 2001; Sultan et al. 2003) over the western and central Sahel, respectively. This is especially true for WT 2, which is associated with long persistent spells (Fig. 4c) and exhibits a broader spatial scale, characterized by a strong meridional shear about the main axis of the AEJ, known to favor the development of squall lines (Fink and Reiner 2003). At $200 \mathrm{hPa}$ (not shown), WTs 2-4 are characterized by the broad-scale seasonal strengthening of the TEJ during JAS. At $200 \mathrm{hPa}$, WTs
5 and 6 are characterized by weak anomalies over the western Sahel, with some evidence of wave patterns near $30^{\circ} \mathrm{N}$ (not shown).

In terms of low-level vertical structure, the troughs and ridges in WTs 2-6 exhibit an eastward tilt with height between 925 and $700 \mathrm{hPa}$, and thus tilt against the mean vertical shear of the AEJ, consistent with positive baroclinic energy conversions, as seen in the AEW normal-mode calculations of Hall et al. (2006). In addition, the convergence anomalies at $700 \mathrm{hPa}$ tend to overly divergent anomalies at $925 \mathrm{hPa}$ and vice versa, as found by Kiladis et al. (2006) in AEWs at $15^{\circ} \mathrm{N}$. The WT composites of anomalous divergence change sign again at $200 \mathrm{hPa}$ (not shown). Differential vorticity advection by the mean vertical shear flow can account for this kind of vertical "checkerboard" structure in AEWs (Thorncroft and Hoskins 1994), while rain evaporation may also contribute to the implied subsidence anomalies at $925 \mathrm{hPa}$ (Kiladis et al. 2006).

Composites for the late-season WTs are shown in 
(a) WT $2(700 \mathrm{hPa})$

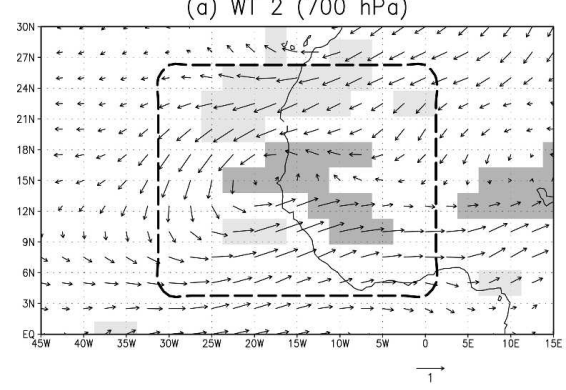

(b) WT $3(700 \mathrm{hPa})$

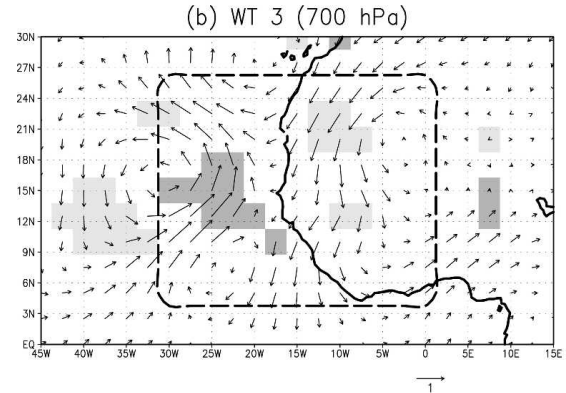

(d) WT $5(700 \mathrm{hPa})$

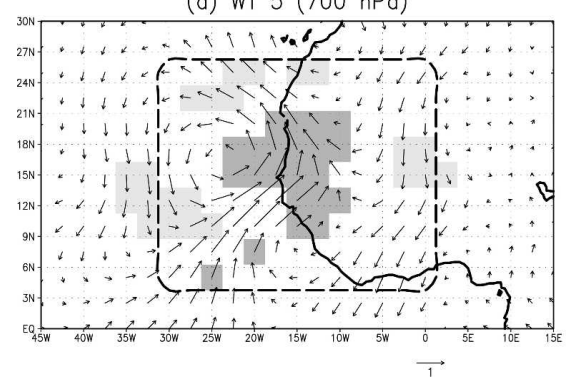

(c) WT $4(700 \mathrm{hPa})$

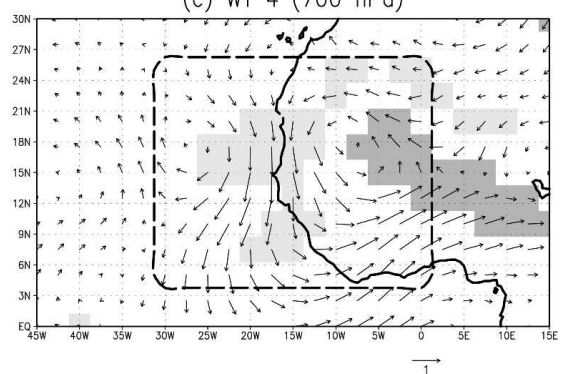

(e) WT $6(700 \mathrm{hPa})$

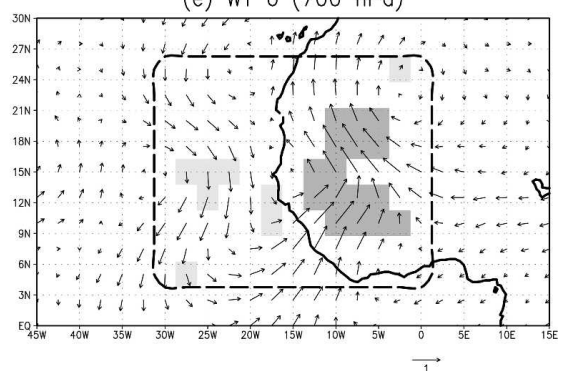

FIG. 7. Same as in Fig. 6 but for 700-hPa anomaly winds.

Fig. 8 over a broader region to highlight possible connections with the midlatitude circulation in the transition season. A strengthening and/or southward shift of the AEJ at $700 \mathrm{hPa}$ is visible near $9^{\circ} \mathrm{N}$ in both WTs (Figs. 8a,b). At $925 \mathrm{hPa}$, an anomalous anticyclonic center characterizes both WTs 7 and 8, with anomalous northeasterlies over western and central Sahel (Figs. $8 \mathrm{c}, \mathrm{d})$. At $200 \mathrm{hPa}$, both WTs are characterized by a broad-scale westerly anomaly associated with the disappearance of the TEJ at the end of the JAS season (not shown; cf. Fig. 2d). A trough in the subtropical westerly jet near the African coast occurs in WT 8, while a slight anomalous ridging there is found in WT 7. These westerly anomalies are vertically extensive and visible at $700 \mathrm{hPa}$, though with large differences between states 7 and 8 over Senegal (Figs. 8a,b). This pattern could be associated with rainy events in boreal autumn, or even winter, from Senegal to Morocco (Knippertz 2003; Knippertz and Martin 2005). As for other weather types, there is again a vertical phase re- versal in the anomalous divergence field between 700 and $925 \mathrm{hPa}$ (Fig. 8).

\section{d. Relationship between the weather states and rainfall occurrence}

A central objective of this study is to relate the above circulation regimes to rainfall over Senegal. Figure 9 shows the spatial distribution of daily rainfall occurrence as anomalies relative to the long-term mean. Note that daily mean intensity of rainfall (i.e., mean rainfall amount during wet days $>1 \mathrm{~mm}$ ) is poorly partitioned amongst the clusters (not shown). Weather types (WTs) 1, 4, and 7 are the driest, and WTs 2, 5, and 6 the wettest. This basic differentiation is partly related to their seasonality since the seasonal cycle of rainfall (Figs. 1b,c) has been retained in the rainfall time series. However, WT1 is clearly identified with dry spells during the core of the JAS season as well (Fig. 4a). The westward-moving wave WT sequences depicted in Figs. 6 and 7 are indeed consistent with a westward-moving 

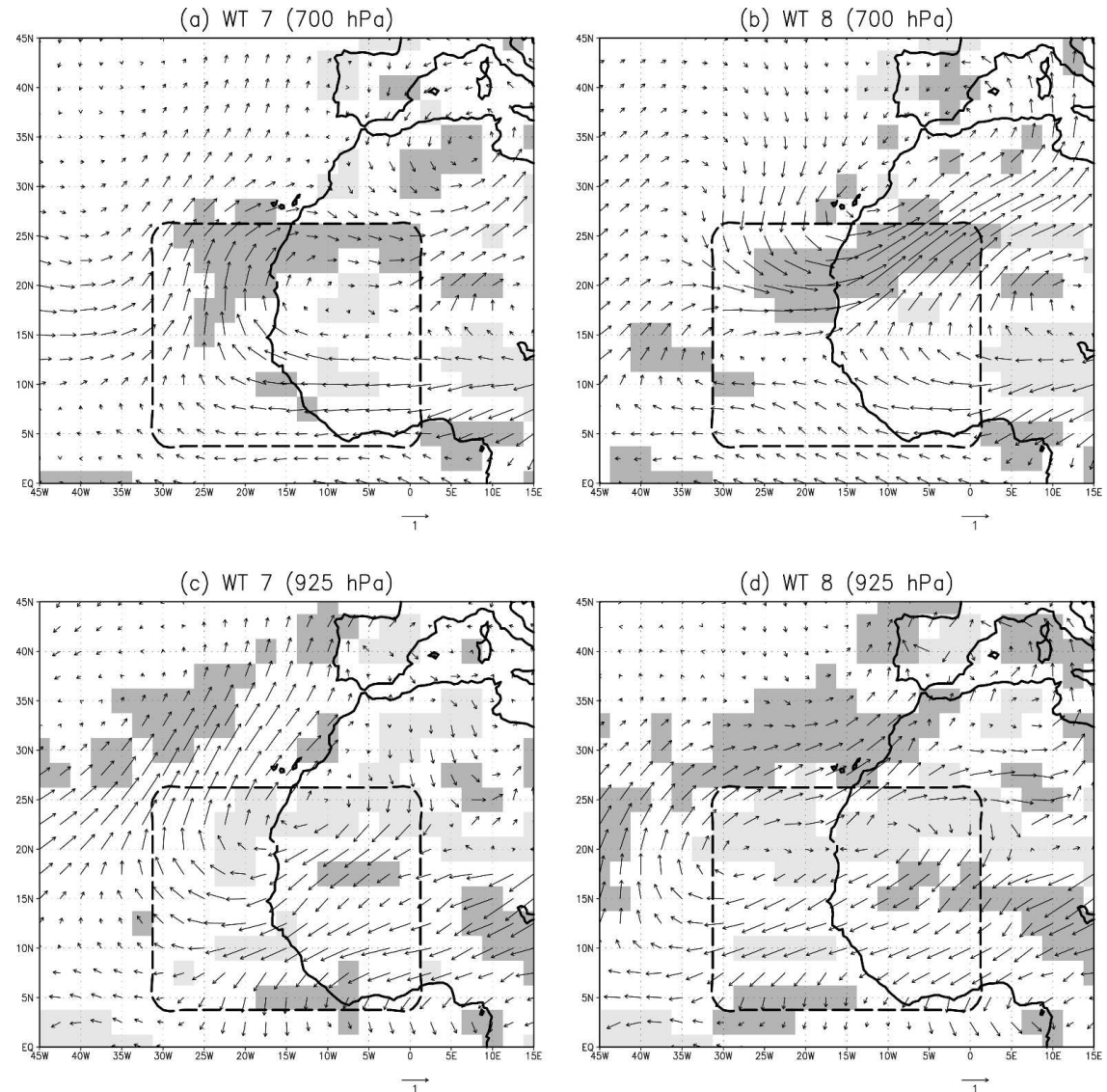

FIG. 8. Composite maps of anomaly winds and divergence for WTs 7 and 8: (a) $700 \mathrm{hPa}$ for WT 7, (b) $700 \mathrm{hPa}$ for WT 8, (c) $925 \mathrm{hPa}$ for WT 7, and (d) $925 \mathrm{hPa}$ for WT 8. Details as in Fig. 5.

rain event. Station rainfall anomalies are broadly consistent with the accompanying divergence anomalies at $700 \mathrm{hPa}$ (Figs. 5, 7, 8). The positive rainfall anomalies in WTs 2, 5, and 6 coincide with anomalous convergence and southwesterly flow at $700 \mathrm{hPa}$, while the negative rainfall anomalies in WTs 1,3 , and 4 coincide with anomalous $700-\mathrm{hPa}$ divergence and are located within the northerly or northwesterly anomalies at $700 \mathrm{hPa}$. These relationships are consistent with the findings of Kiladis et al. (2006) for AEWs identified at $15^{\circ} \mathrm{N}$. WTs 7 and 8 are anomalously dry with respect to the seasonal average, consistent with their seasonality (Fig. 4a). However, WT 8 is anomalously wet with respect to the late-September average.

\section{e. Interannual variability of weather types and seasonal rainfall in Senegal}

The connection between weather type and rainfall occurrence over Senegal suggests that it may be possible to use the weather types as a tool to interpret seasonal-scale rainfall anomalies in terms of year-toyear anomalies in weather-type frequency. In the following, "seasonal rainfall" will refer to seasonal rainfall occurrence frequency. Considering seasonal rainfall amounts instead of rainfall occurrence leads to similar results (not shown), but with slightly weaker relationships for amounts. This is consistent with the slightly higher spatial coherence and potential predictability of rainfall frequency compared to seasonal amount (Moron et al. 2006, 2007).

Figure 10 shows the relationship between the frequency occurrence of each WT and seasonal rainfall, for the 10 driest and wettest years, identified from the standardized anomaly index (SAI) of rainfall occurrence. The SAI is defined as the station average of the standardized anomalies obtained by subtracting the mean and dividing by the interannual standard deviation at each station. For the "seasonal" WTs 1, 2, and 8 , the differences in WT frequency between the two sets of years are consistent with the mean rainfall anomaly of each WT (Fig. 9). Thus the 10 driest 
(a) WT 1

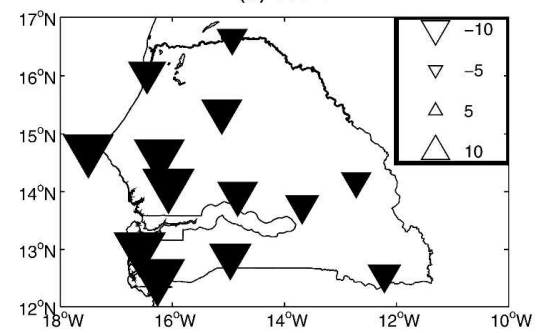

(c) WT 3

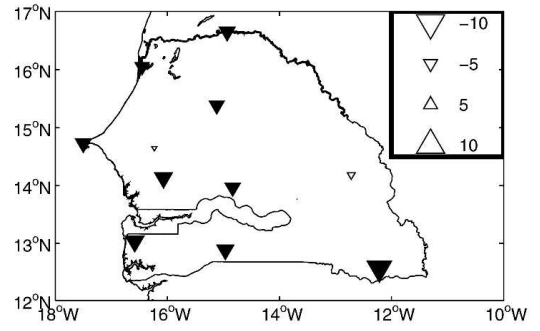

(e) WT 5

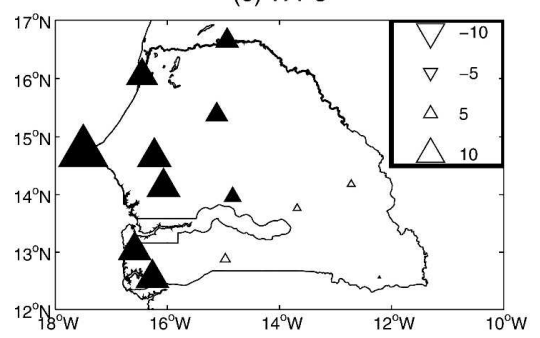

(g) WT 7

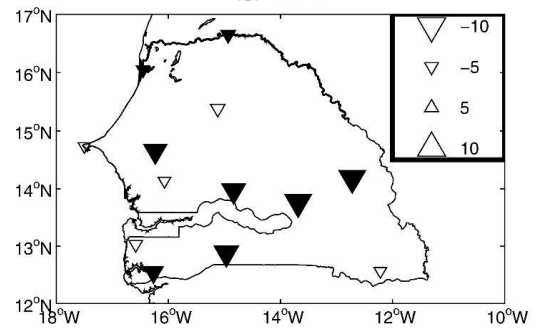

(b) WT 2

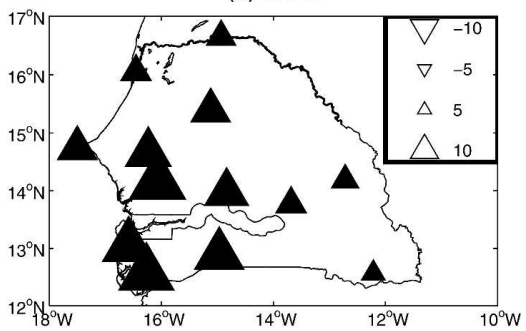

(d) WT 4

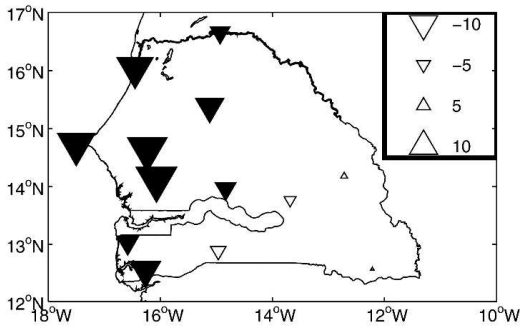

(f) WT 6

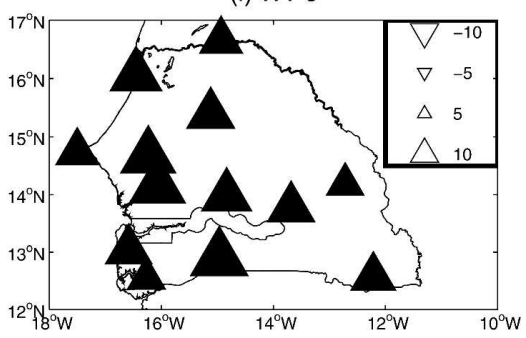

(h) WT 8

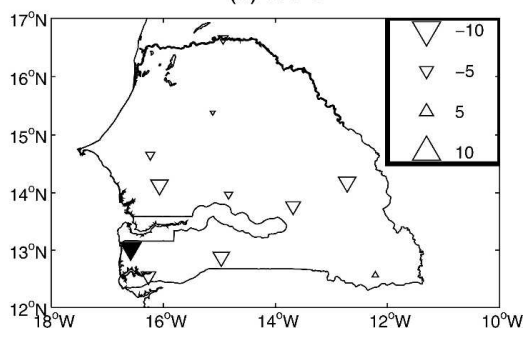

FIG. 9. Rainfall occurrence anomalies (\%) associated for (a) WT 1, (b) WT 2, (c) WT 3, (d) WT 4, (e) WT 5, (f) WT 6, (g) WT 7, and (h) WT 8. Significant values at the one-sided 99\% level according to a chi-square test (null hypothesis is that the probability of rainfall $>1 \mathrm{~mm}$ during the days belonging to a given WT is the same as that of the remaining days) are filled in black.

years contain more of WTs 1 and 8 , but less of WT 2 (Figs. 10a,b,h).

Differences in frequency of WTs 4-7 are not significant overall between the wet and dry years, although shifts in WT seasonality can be identified (Figs. 10d-g). There are slightly more WT 6 in dry years (Fig. 10f). Weather type 6 is associated with wet anomalies but its increased prevalence is concentrated in September, when rainfall occurrence is climatologically low (Fig. 1b). The relationship between WT3 and seasonal rainfall is complex. On average, this WT is accompanied by weakly negative rainfall anomalies (Fig. 9c), yet there are clearly more WT 3 days in wet years than in dry years (Fig. 10c). This can be explained by differences in transition probabilities into WT 3 (Fig. 4b) between the two sets of years, with more-frequent transitions from state 5 in dry years. WT 3 days exhibit $10 \%-40 \%$ higher rainfall probabilities when they follow WT 2 as opposed to WT 5. 
(a) WT 1
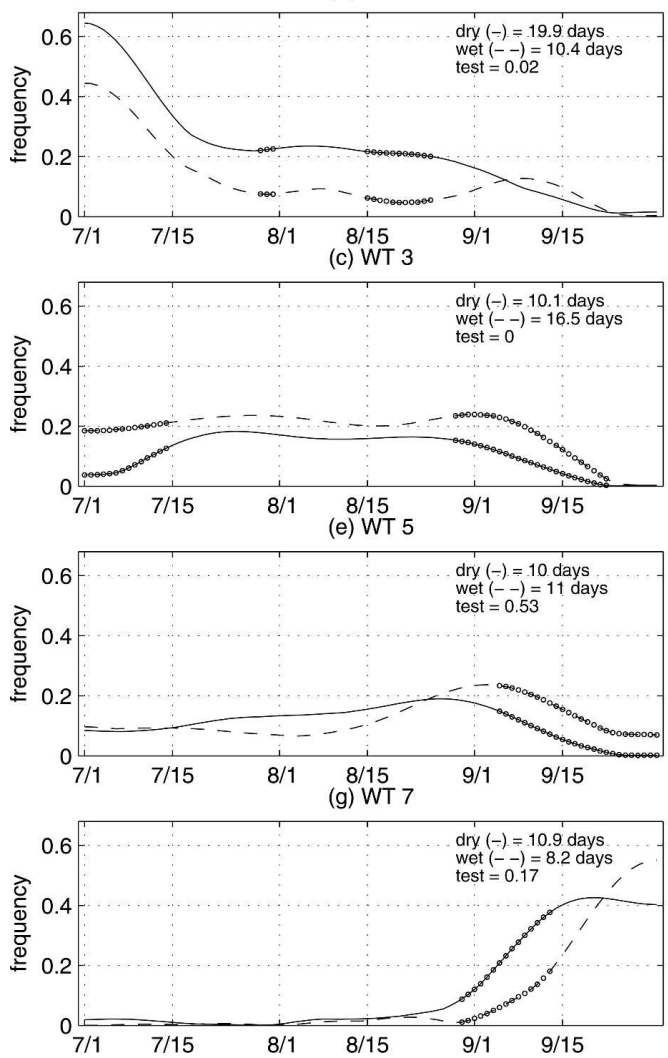

(b) WT 2
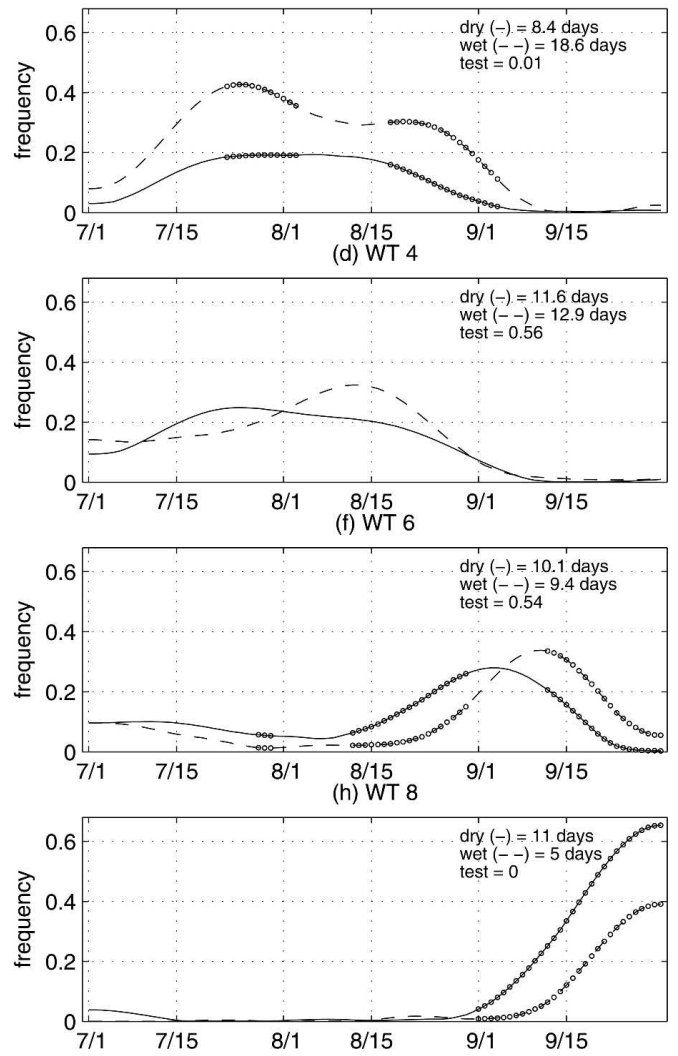

FIG. 10. Mean seasonal cycle of WT frequency for the 10 driest (full line) and 10 wettest (dashed line) JAS seasons. The selected seasons are determined from the standardized anomaly index of rainfall occurrence. The WT frequency was computed on a daily basis from each sample of $10 \mathrm{yr}$, and then smoothed for clarity using a recursive low-pass filter retaining only frequencies lower than $1 / 30$ cycles per day. A dot on each curve indicates a significant difference between both samples at the two-sided 95\% level according to a Student's $t$ test (the null hypothesis is that the mean frequency of both samples is equal). The mean occurrence frequency for each WT during the 10 driest and 10 wettest seasons are indicated (in days per JAS season) in the upper right corner of each panel, along with the Student's $t$ test $p$ value of the difference between dry and wet samples.

\section{f. Canonical correlation analysis}

Year-to-year changes in WT frequency clearly cannot account for all interannual variability of rainfall. Even if the frequency of a WT remains constant, it may be associated with wetter conditions in some years than others. In this subsection we estimate the relative importance of changes in WT frequency versus changes in WT "character" (i.e., its rainfall characteristics), for interannual rainfall variability over Senegal. As in the preceding section, we confine our attention to rainfall occurrence only. Similar results are obtained using amounts, with a slight decrease of skill.

The number of wet days $N_{i, j}$ in year $i$ at station $j$ can be decomposed into the rainfall probability for each weather type $p_{i, j, k}$ in year $i$ at station $j$, multiplied by the frequency of each weather type $n_{i, k}$ during that year,

$$
N_{i, j}=\sum_{k=1}^{8} p_{i, j, k} n_{i, k} .
$$

Two complementary canonical correlation analyses (CCA; Barnett and Preisendorfer 1987; Ward and Navarra 1997; Moron et al. 2001) are made to estimate the contribution of $n_{i, k}$ (i.e., WT frequency) and $p_{i, j, k}$ (i.e., WT character) in explaining $N_{i, j}$. The first CCA is made between $n_{i, k}$ and $N_{i, j}$, so that WT frequency is used to "predict" interannual variability in rainfall frequency. The second CCA uses $p_{i, j, k}$ averaged over stations as the predictor of $N_{i, j}$. Both CCAs are applied using cross validation, leaving out five consecutive years each time, and computing the CCA on the remaining $33 \mathrm{yr}$. We restrict our attention to the leading CCA mode in each case, since inclusion of subsequent modes is not found to significantly increase the skill. 
(a) MOS skill of rainfall occurrence

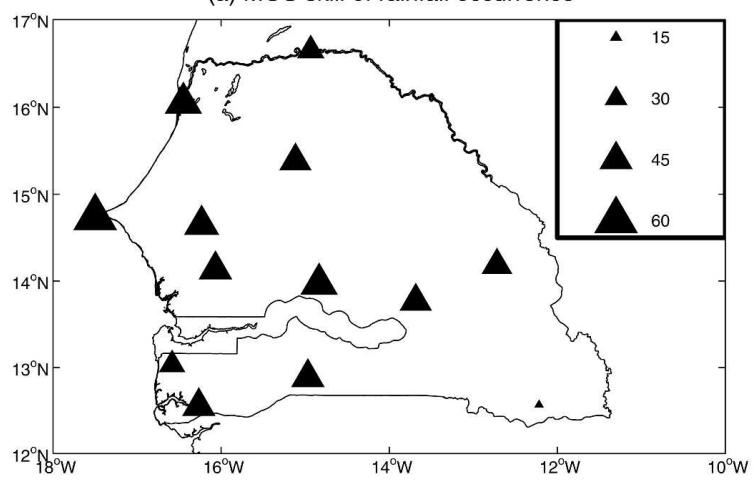

(b) CCA\#1 of weather type frequency

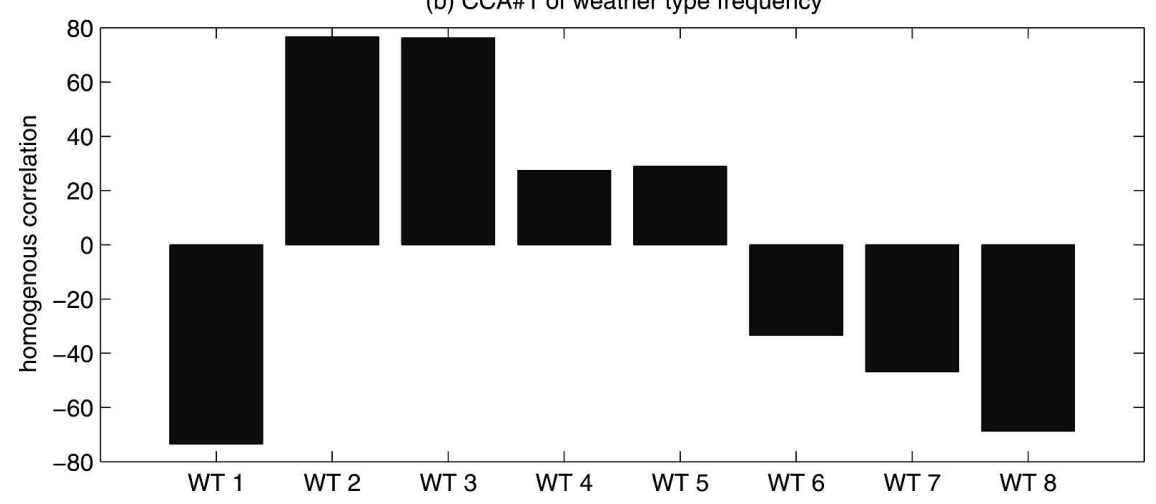

(c) CCA\#1 time scores

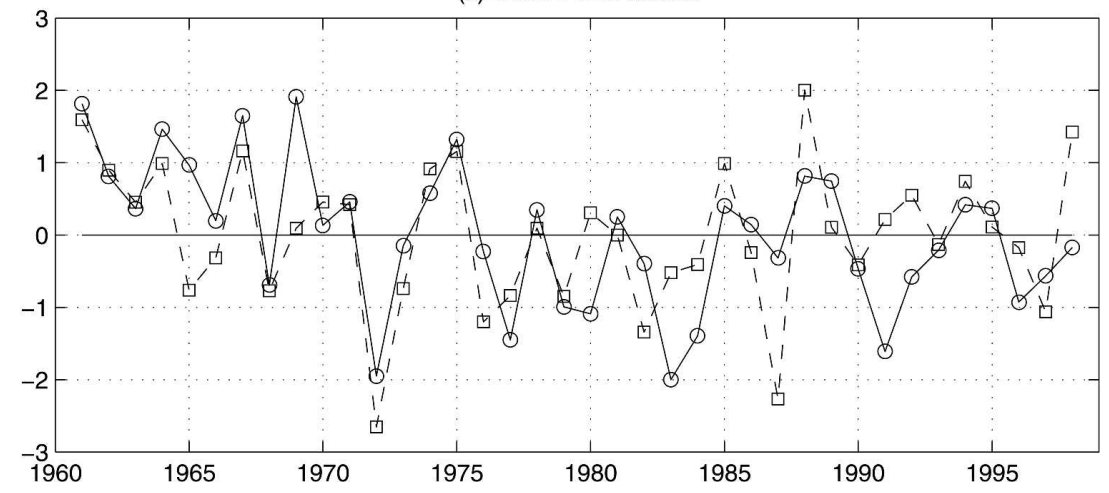

FIG. 11. Leading mode of a cross-validated CCA between interannual anomalies of weather-type frequency and station rainfall frequency: (a) correlations $\times 100$ between the observed and "predicted" rainfall frequency; (b) homogeneous correlation $\times 100$ of weathertype frequency; (c) CCA time series of weather-type frequency (dashed line and square) and station rainfall frequency (solid line and circle) in standardized values. The homogenous correlations in (b) are the correlations $\times 100$ between weather-type frequency and the crossvalidated time series associated with its CCA pattern [dashed line in (c)].

Results of the first CCA between $n_{i, k}$ and $N_{i, j}$ are presented in Fig. 11, in terms of (a) correlation between the "predicted" and observed rainfall occurrence frequency $N_{i, j}$ at each station, (b) the loading of each WT's frequency $n_{i, k}$, and (c) the cross-validated CCA time scores. In Fig. 11a, the "prediction" is equivalent to the cross-validated model output statistics (MOS) skill (Ward and Navarra 1997; Moron et al. 2001). The skill of WT frequency is spatially homogenous, with values between 0.36 and 0.60, except at Kedougou in the ex- 
(a) MOS skill of rainfall occurrence

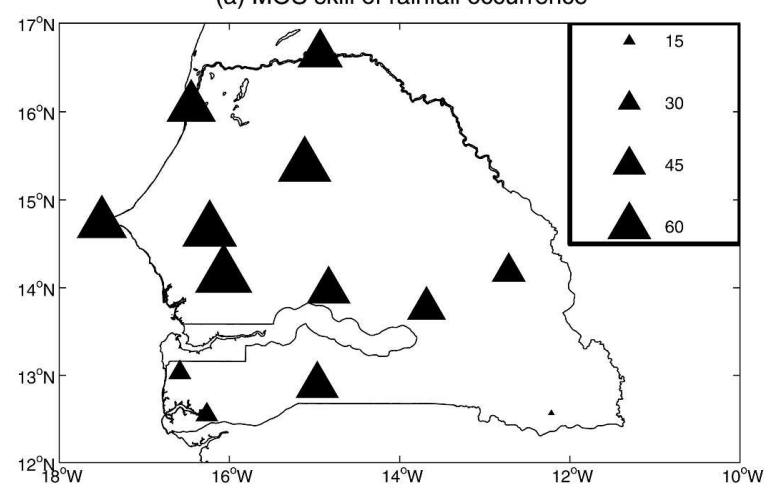

(b) CCA\#1 of probability of rainfall

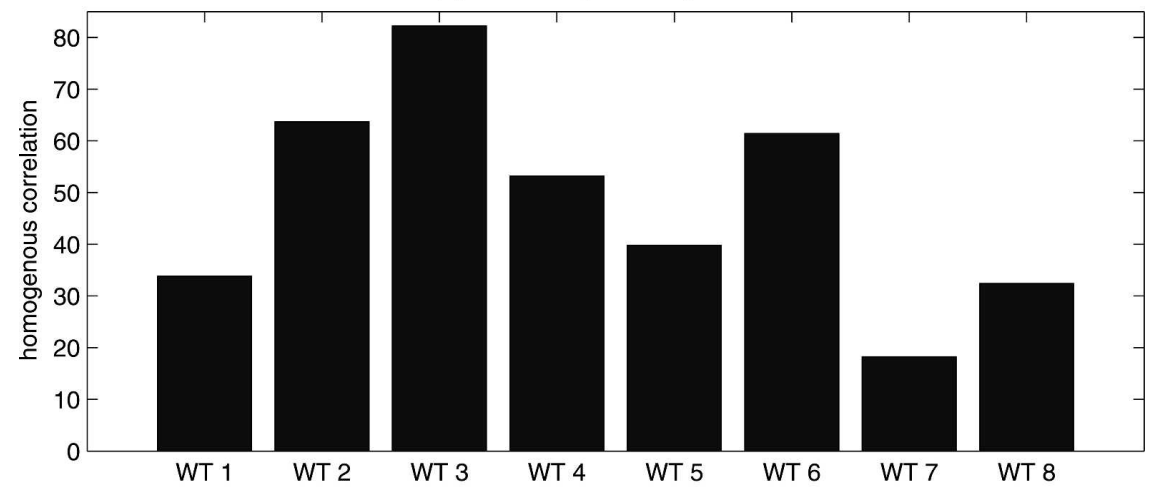

(c) CCA\#1 time scores

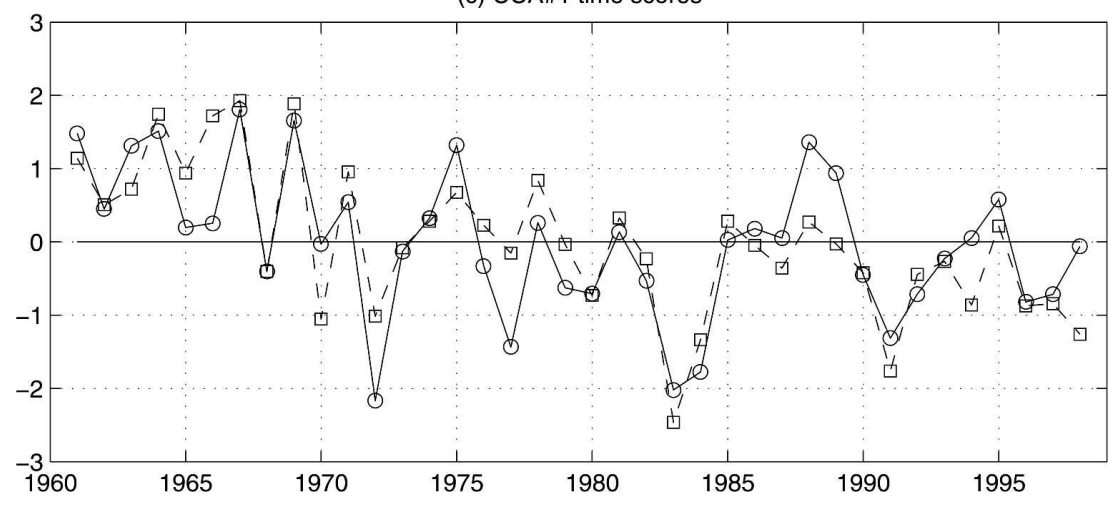

FIG. 12. Leading mode of a cross-validated CCA between interannual anomalies of the average rainfall probability within each weather type and station rainfall frequency: (a) correlations between the observed and "predicted" rainfall frequency; (b) homogeneous correlation $\times 100$ of weather-type average rainfall probability; (c) CCA time series of weather-type average rainfall probability (dashed line and square) and frequency of occurrence of rainfall (solid line and circle) in standardized values. The homogenous correlations in (b) are the correlations $\times 100$ between rainfall probability within each weather type and the crossvalidated time series associated with its CCA pattern [dashed line in (c)].

treme southeast of the country (Fig. 11a). The WT loadings are characterized by large positive loadings for WTs 2 and 3, and strong negative loadings for WTs 1 and 8 (Fig. 11b). Thus, changes in WT frequency during the onset and end phases of the monsoon (WTs 1 and 8 ), breaks in the monsoon (WT 1), and surges during the core of the JAS season (WT 2) exert the largest impact on the interannual variability of rainfall fre- 
quency. This seasonality is brought out in the composite analysis of the 10 driest and wettest years in Fig. 10, which is consistent with the CCA result. Changes in the frequency of the WTs, interpreted mainly as phases of westward-moving AEWs, on the other hand, are not significant in explaining the interannual variability of rainfall (Fig. 11b).

The temporal scores (Fig. 11c) suggest that the intensity of the link between WT frequency and rainfall occurrence has weakened since 1980 . The correlation between both CCA time series is 0.60 for the whole period, but drops from 0.81 in $1961-79$ to only 0.36 in 1980-98.

Figure 12 presents the complementary CCA between $N_{i, j}$ and the year-to-year changes in the probability of rainfall within each weather type, averaged over stations ${\overline{p_{i, j, k}}}^{j}$. In this case rainfall probabilities enter into both $N_{i, j}$ and $\overline{p_{i, j, k}}$ so that the resulting "skill" should be interpreted as the extent to which interannual rainfall anomalies at the station level can be accounted for by year-to-year changes in average rainfall probability of each state, rather than evidence of predictability. The skill values, using $\overline{p_{i, j, k}}$ as the predictor (Fig. 12a), are somewhat higher than those in Fig. 11a, especially in the central-northern part of Senegal. In this case, the loadings of each WT (Fig. 12b) are consistently positive with largest values for WTs whose frequency peaks in the core of the JAS season. The correlation between cross-validated CCA temporal scores is 0.80 (Fig. 12c) with similar values for the first and second halves of the time series ( 0.79 and 0.81 , respectively).

The predictions of station-average SAI of rainfall occurrence made with the two CCA analyses are plotted in Fig. 13, together with the observed SAI. The two predictions are seen to be quite independent $(r=0.28)$. During certain years, such as the 1972 dry year, the contribution of WT frequency is particularly large, mostly associated with an abundance of "dry" WT 1 (41 days) and no wet WT 2. However, the discrepancy between observed SAI and its prediction from WT frequency is large in 1965, 1980, 1982, 1987, 1991, and 1992 , where year-to-year changes in $p_{i, j, k}$ are clearly important. The low-frequency component of the CCA predictions is plotted in Fig. 13b. Changes in WT character $p_{i, j, k}$ seem more important in accounting for decadal variability of rainfall frequency over the Sahel.

\section{g. Relationships with sea surface temperature}

To gain further insight, we plot correlations between the CCA modes and SST in Fig. 14. Correlations with the observed SAI (Fig. 14a) show the well-known
SSTA structure familiar from previous analyses of Sahelian rainfall (i.e., Fontaine and Bigot 1993; Rowell et al. 1995; Ward 1998; Janicot et al. 2001). Positive rainfall anomalies are associated with La Niña-like SST anomalies over the tropical Pacific, cold SSTAs over the Indian Ocean, and warm SSTAs over the tropical North Atlantic. As noted by Rowell (2001), the highest correlations in tropical Pacific are shifted south of the equator relative to the canonical ENSO SST pattern (Rasmusson and Carpenter 1982). The fact that correlations are weak over the Atlantic in Fig. 14a could be associated with the relatively short period of the analysis and also the stronger link between tropical Atlantic and Sahelian rainfall in 1950-70 than thereafter (Ward 1998; Janicot et al. 2001). This would tend to underemphasize the multidecadal variability, which is strongly correlated with Atlantic SSTAs (Folland et al. 1986; Rowell et al. 1995).

The SST correlations with the leading CCA mode of WT frequency (Fig. 14b) are very clearly dominated by ENSO. The correlations over the tropical Pacific are now almost symmetric relative to the equator and match the canonical ENSO pattern (Rasmusson and Carpenter 1982). This pattern also matches the correlations between high-frequency $(<8 \mathrm{yr})$ variations of regional Sahelian index and SST (Rowell et al. 1995; Ward 1998). In contrast, the SST correlations with the complementary leading CCA mode of WT character (Fig. 14c) tend to resemble the other aspects of the correlations with the SAI over the Atlantic, west Pacific, and Indian Oceans. Indeed, the correlation pattern in Fig. 14c resembles the lowfrequency (>8 yr) SST pattern identified by Rowell et al. (1995) and Ward (1998). Over the tropical Pacific, the equatorial correlations are close to zero, with the highest values clearly shifted south of the equator.

The analysis of SST correlations provides further evidence that the influence of ENSO on Senegal rainfall is largely through changes in WT frequency, while the character of the rainfall associated with the WTs themselves undergoes important modulation at decadal time scales.

\section{Summary and discussion}

\section{a. Summary}

An objective classification procedure using the $k$ means algorithm was used to summarize the unfiltered daily atmospheric variability during the boreal summer season 1961-98 over the western Sahel and eastern tropical North Atlantic $\left(5^{\circ}-25^{\circ} \mathrm{N}, 0^{\circ}-30^{\circ} \mathrm{W}\right)$. The clustering scheme was based on regional gridded wind 
(a) observed and estimated $S A I$ of rainfall occurrence

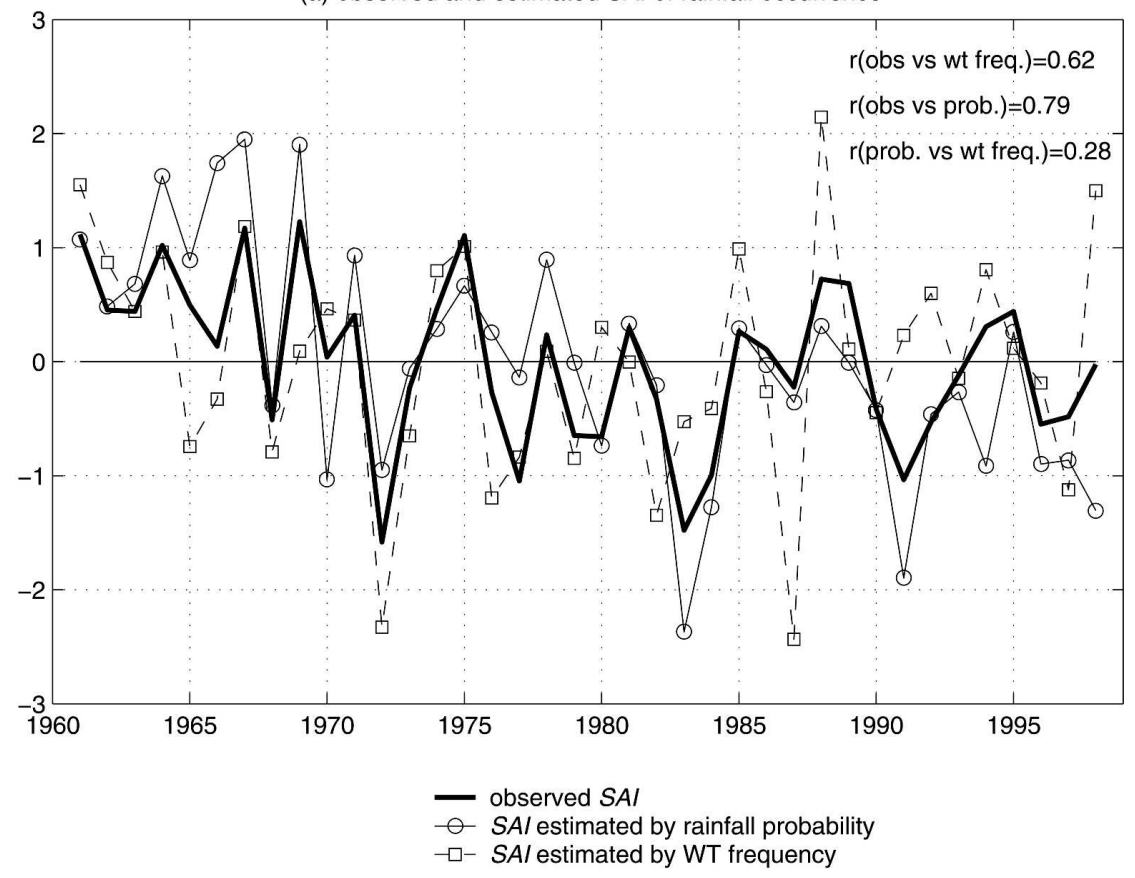

(b) LF ( $>8$ years) variability of observed and estimated $S A$ l of rainfall occurrence

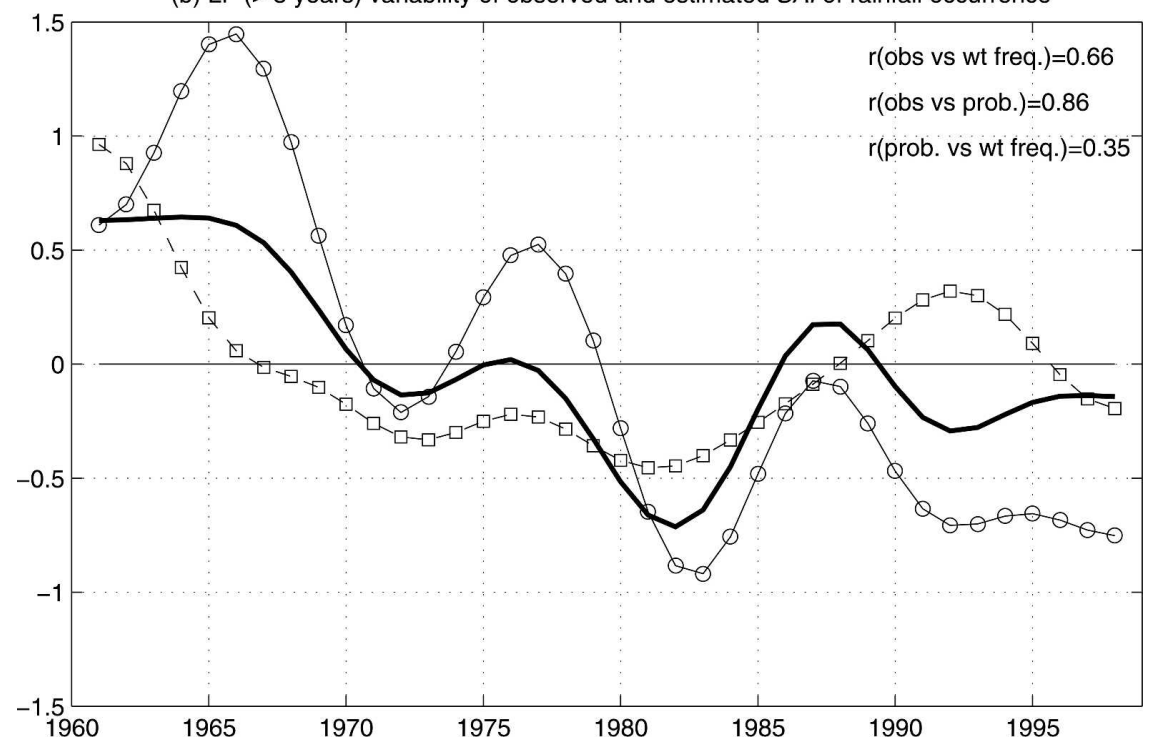

FIG. 13. (a) Standardized anomaly index of observed rainfall frequency (thick line), estimated rainfall frequency hindcast by the CCA between rainfall frequency and average probability of rainfall occurrence of each weather type (full line + circle), and by the CCA between rainfall frequency and weather-type frequency (dotted line + square). (b) Same as in (a) but for the low-frequency component. The low frequency is extracted by a recursive low-pass filter removing high frequencies higher than $1 / 8$ cycles $\mathrm{yr}^{-1}$.

fields from the daily ERA-40 reanalyses of the monsoon flow at $925 \mathrm{hPa}$, the African easterly jet level at $700 \mathrm{hPa}$, and the tropical easterly jet level at $200 \mathrm{hPa}$. An eight-cluster solution was shown to offer a good balance between the discrimination of daily rainfall
(Fig. 9) and physical interpretation of the associated atmospheric circulation patterns (Figs. 5-8).

Three of the weather types were found to correspond primarily to the onset (WT 1; Fig. 5) and end of the monsoon season (WTs 7 and 8; Fig. 8). WT 1 was also 
(a)

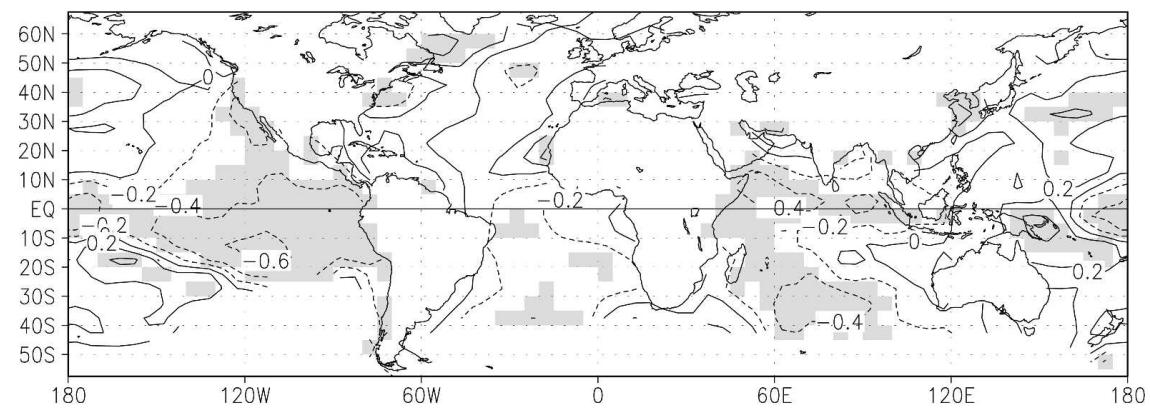

(b)

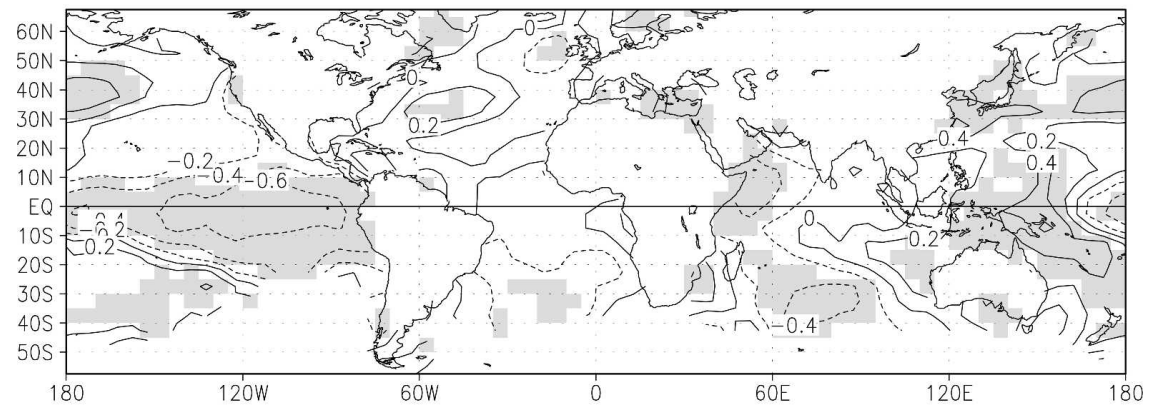

(c)

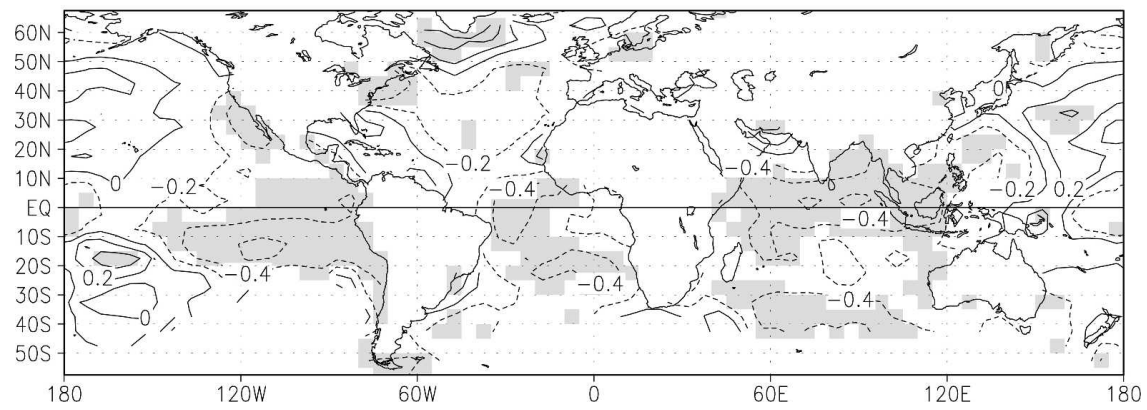

FIG. 14. Correlation between observed SST in JAS and (a) observed SAI (from rainfall occurrence $>1 \mathrm{~mm}$ ), (b) leading CCA mode of the weather-type frequency (dashed line with squares in Fig. 11c), and (c) leading CCA mode of the average probability of rainfall of each weather type (dashed line with squares in Fig. 12c). The contours are indicated at $-0.6,-0.4,-0.2,0,0.2,0.4$, and 0.6 , and shadings indicate local significant correlations at the two-sided $95 \%$ level according to a random-phase test (Janicot et al. 1996; Ebisuzaki 1997).

found to be associated with dry spells during the core of the JAS season (Fig. 4). WT 8 may be associated with late-season interactions with the extratropics (Fig. 8), leading to scattered rainfall mainly over northwest Senegal.

Weather types 2-6 were found to be primarily associated with westward-moving easterly waves and monsoon surges (Figs. 6 and 7). They are most prevalent from mid-July to mid-September (Fig. 4a) and are generally less persistent than WTs 1,7 , and 8 , with the exception of WT 2 (Fig. 4c). Two main circuits of transition between these weather types were identified, with $2 \rightarrow 3 \rightarrow 4 \rightarrow 2$ predominant during the first part of the JAS season and $3 \rightarrow 4 \rightarrow 6 \rightarrow 5 \rightarrow 3$ during the second part (Fig. 4b). Both circuits are consistent with a westward-moving easterly waves (period 3-9 days and wavelength 2000-3000 km). WT 2 exhibits longer spells of 3-7 days (Fig. 4c) and a pattern characteristic of the monsoon surge over western Sahel (Fig. 6a).

Weather types 2, 5, and 6 were found to be charac- 
terized by anomalously high rainfall occurrence over Senegal (Figs. 9b,e,f) with WT 3, and particularly WT 4, being anomalously dry (Figs. 9c,d). However, these relationships with rainfall are not unique. For example, WT 3 tends to be anomalously dry when it follows WT 5 , but anomalously wet when it follows WT 2 . The more frequent $5 \rightarrow 3$ transition leads to a weak, negative mean rainfall anomaly associated with WT 3 (Fig. 9c). Note that mean daily intensity is poorly partitioned amongst the clusters, consistent with the spatial coherence at interannual scale being primarily conveyed by the frequency of occurrence (Moron et al. 2006, 2007).

Canonical correlation analysis was used to quantify the extent to which the interannual variability of rainfall occurrence is related to the occurrence frequency of weather types versus year-to-year changes in the rainfall character of the weather types. The frequency of early and late-season weather types (WTs 1, 7, and 8), as well as the frequency of the long-lasting spells of WT 2 , were found to be strongly related to seasonal-average frequency of wet days $>1 \mathrm{~mm}$, particularly in central and northern Senegal. By contrast, the frequencies of westward-moving wave disturbances (WTs 4-6), were not found to have a significant impact on interannual rainfall variability (Figs. 11 and 12), consistent with previous findings (i.e., Rowell 2001; Fink and Reiner 2003; Fink et al. 2004).

The component of seasonal rainfall associated with changes in WT frequency was found to be strongly related to ENSO (Fig. 14b). El Niño events tend to be associated with more (less) WTs 1,7 , and 8 (WTs 2 and 3 ) and vice versa for La Niña events. The complementary component not explained by weather-type frequency is characterized by a consistent increase/ decrease of probability of rainfall for each WT, especially those that occur during the core of the JAS season (Fig. 12b). This signal explains a larger part of the interannual variance of the country-averaged rainfall occurrence. It was found to be less related to ENSO, and to have a stronger decadal component (Fig. 14c).

\section{b. Discussion}

Our findings demonstrate that weather typing using cluster analysis of daily circulation fields over the western Sahel and neighboring tropical northern Atlantic is able to recover the main features of circulation variability, without the need to resort to explicit time filtering of the data, as is commonly done. The resulting description gives an integrated view of the complex regional-scale atmospheric circulation features on a mix of different spatial (e.g., meridional migration of the ITCZ, westward-moving easterly waves, persistent monsoon surges and breaks, tropical-extratropical in- teractions) and temporal (e.g., seasonal cycle, subseasonal variability, etc.) scales. Weather type 1 is of particular interest in this respect, being associated with both the premonsoonal seasonal dryness in early July as well as monsoon breaks during the core monsoon season. Weather types 2-6 show many of the hallmarks of the AEW regression patterns constructed from filtered ERA-15 data by Kiladis et al. (2006), when the base point was chosen to be at $15^{\circ} \mathrm{N}$-consistent with the latitude of the wave centers of the weather types. Thus, positive rainfall anomalies (WTs 2, 5, and 6) are associated with anomalous convergence and southwesterly flow at $700 \mathrm{hPa}$. Below this level, the sign of the divergence anomalies reverses. This phase reversal was found previously for the AEWs identified at $15^{\circ} \mathrm{N}$ by Kiladis et al. (2006) and interpreted in terms of waves on a vertical shear flow. All of our WTs exhibit this structure south of $25^{\circ} \mathrm{N}$.

From the methodological point of view, using discrete clusters to represent propagating atmospheric patterns as AEWs could be questioned. For a certain level of discretization, identified here as six-seven clusters (Fig. 3), distinct weather types mostly represent different phases of the same propagating meteorological feature. The flatness of the classifiability index between 6 and 10 clusters suggests that AEWs will be represented by additional weather types as the number of clusters grows. In this context, the weather types should be interpreted as composite "snapshots" of the different phases of the same atmospheric phenomenon, rather than as distinct atmospheric phenomenon. On the other hand, our approach, which provides a straightforward and objective partitioning of the unfiltered atmospheric variability at various time scales, may be advantageous over Senegal where there is a complex interaction between AEW and monsoonal processes. Thus, the classical AEW normal-mode structure with ascent in the northerlies (Thorncroft and Hoskins 1994; Hall et al. 2006) is not what would be expected in a monsoon surge. Observational AEW studies paint a more complex picture; for example, Kiladis et al. (2006) found ascent in various phases of waves identified at $10^{\circ} \mathrm{N}$, while waves identified at $15^{\circ} \mathrm{N}$ exhibited ascent consistently in the southerlies. Our results are consistent with the latter, which may reflect the mix of AEW and monsoonal processes.

The discrimination of station rainfall frequency by the circulation-based weather types appears promising, but it will be of interest to compare the benefits of this approach with a state classification based directly on the station rainfall observations themselves, such as with hidden Markov models (HMM; e.g., Robertson et al. 2006). A match between weather typing and HMM 
state classifications would only be expected if localscale rainfall is uniquely conditioned by the larger-scale atmospheric circulation. On the other hand, two similar regional-scale patterns may not necessarily be associated with the same station rainfall pattern and vice versa. The degree of complexity may vary significantly across the tropics, depending on the rainfall-generating phenomena. The performance of weather typing and HMM approaches to downscaling from a GCM is explored in Part II of this study.

A potentially important result provided by the weather typing is the separation of interannual rainfall variance into a component that is associated with yearto-year changes in weather-type frequency, and a component that is not. The component of rainfall associated with weather-type frequency largely accounts for the relationship between Senegal rainfall and ENSO. The weather types more prevalent during warm ENSO events are all associated with enhanced northeasterlies at low levels over the western Sahel and/or the neighboring tropical North Atlantic, consistent with previous findings at the seasonal time scale (i.e., Trzaska et al. 1996; Janicot et al. 1998, 2001; Rowell 2001). Our finding that seasonal rainfall anomalies associated with year-to-year changes in the frequency of westwardmoving wave weather types is unrelated to ENSO is consistent with the conclusion of Rowell (2001). The relationship between the weather-type frequency and rainfall variability appears to weaken after 1980, and further work is needed to determine whether this is more than just random sampling variability (Moron et al. 2003; Moron 2005).

The component of country-averaged rainfall occurrence not associated with weather-type frequency accounts for a larger part of the interannual rainfall variance. It appears to be stronger on longer time scales, and may be the key factor in accounting for trends in Sahelian rainfall. This component could perhaps be associated with a large-scale variation of a circulationindependent process linked to rainfall, such as the availability of moisture, while the ENSO teleconnection is more dynamical. However, the interpretation remains speculative because of the short 1961-98 record of daily station rainfall available. The relationship between the rainfall character of the weather types and other reanalysis variables remains to be explored.

This study provides a framework for downscaling the local rainfall from atmospheric circulation patterns. If a GCM is able to simulate these weather types with sufficient accuracy, together with aspects of their temporal variability, transfer functions could be used to associate these regional-scale patterns with local-scale rainfall. This is explored in Part II of this study.
Acknowledgments. We thank DMN-Senegal for providing the daily rainfall dataset for Senegal and B. Fontaine, B. Sultan, P. Knippertz, A. Giannini, and S. Trzaska for their insightful comments at various stages of this study. We thank also the editor (David Straus) and the four anonymous reviewers whose constructive comments lead to a substantially improved manuscript. ECMWF ERA-40 wind data used in this study have been obtained from the ECMWF data server (http://data.ecmwf.int/data/d/era40_daily/). This paper is funded by a Cooperative Agreement from the National Oceanic and Atmospheric Administration NA05OAR 4311004 and by Department of Energy Grant DE-FG02-02ER63413. The views expressed herein are those of the author(s) and do not necessarily reflect the views of NOAA or any of its subagencies.

\section{REFERENCES}

Barnett, T. P., and R. Preisendorfer, 1987: Origins and levels of monthly and seasonal forecast skill for United States surface air temperatures determined by canonical correlation analysis. Mon. Wea. Rev., 115, 1825-1850.

Burpee, R. W., 1972: The origin and structure of easterly waves in the lower troposphere of North Africa. J. Atmos. Sci., 29, 77-90.

Camberlin, P., and M. Diop, 1999: Interrelationships between groundnut yield in Senegal, interannual rainfall variability and sea surface temperatures. Theor. Appl. Climatol., 63, 163-181.

— , and — 2003: Application of daily rainfall principal component analysis to the assessment of the rainy season characteristics in Senegal. Climate Res., 23, 159-168.

D'Amato, N., and T. Lebel, 1998: On the characteristics of the rainfall events in the Sahel with a view to the analysis of climatic variability. Int. J. Climatol., 18, 955-974.

Diday, E., and J. C. Simon, 1976: Clustering analysis. Digital Pattern Recognition, K. S. Fu, Ed., Vol. 10, Communication and Cybernetics, Springer-Verlag, 47-94.

Diedhiou, A., S. Janicot, A. Viltard, and P. de Felice, 1998: Evidence of two regimes of easterly waves over West Africa and the tropical Atlantic. Geophys. Res. Lett., 25, 2805-2808.

,,,$--- \ldots$, and H. Laurent, 1999: Easterly wave regimes and associated convection over West Africa and tropical Atlantic: Results from the NCEP/NCAR and ECMWF reanalyses. Climate Dyn., 15, 795-822.

$-, \ldots,-$, and — -2001 : Composite patterns of easterly disturbances over West Africa and the tropical Atlantic: A climatology from the 1979-95 NCEP/NCAR reanalyses. Climate Dyn., 18, 241-253.

Druyan, L. M., M. Fulakeza, and P. Lonergan, 2006: Mesoscale analyses of West African summer climate: Focus on wave disturbances. Climate Dyn., 27, 459-481.

Ebisuzaki, W., 1997: A method to estimate the statistical significance of a correlation when the data are serially correlated. J. Climate, 10, 2147-2153.

Fink, A. H., and A. Reiner, 2003: Spatiotemporal variability of the relation between African easterly waves and West African squall lines in 1998 and 1999. J. Geophys. Res., 108, 4332, doi:10.1029/2002JD002816.

_ , D. G. Vincent, P. M. Reiner, and P. Speth, 2004: Mean state 
and wave disturbances during phases I, II, and III of GATE based on ERA-40. Mon. Wea. Rev., 132, 1661-1683.

Folland, C. K., T. N. Palmer, and D. E. Parker, 1986: Sahel rainfall and worldwide sea temperatures, 1901-85. Nature, 320, 602607.

Fontaine, B., and S. Bigot, 1993: West African rainfall deficits and sea surface temperatures. Int. J. Climatol., 13, 271-285.

Ghil, M., and A. W. Robertson, 2002: "Waves" vs. "particles" in the atmosphere's phase space: A pathway to long-range forecasting? Proc. Natl. Acad. Sci. USA, 99, 2493-2500.

Giannini, A., R. Saravanan, and P. Chang, 2003: Oceanic forcing of Sahel rainfall on interannual to interdecadal time scales. Science, 302, 1027-1030.

Grist, J. P., 2002: Easterly waves over Africa. Part I: The seasonal cycle and contrasts between wet and dry years. Mon. Wea. Rev., 130, 197-211.

Gu, G., and R. F. Adler, 2004: Seasonal evolution and variability associated with the West African monsoon system. J. Climate, 17, 3364-3377.

- , - G. J. Huffman, and S. Curtis, 2004: African easterly waves and their association with precipitation. J. Geophys. Res., 109, D04101, doi:10.1029/2003JD003967.

Hall, N. M. J., G. N. Kiladis, and C. D. Thorncroft, 2006: Threedimensional structure and dynamics of African easterly waves. Part II: Dynamical modes. J. Atmos. Sci., 63, 22312245.

Hastenrath, S., 1984: Interannual variability and annual cycle: Mechanisms of circulation and climate in the tropical Atlantic. Mon. Wea. Rev., 112, 1097-1107.

_ 1990: Decadal-scale changes of the circulation in the tropical Atlantic sector associated with Sahel drought. Int. J. Climatol., 10, 459-472.

Janicot, S., and B. Sultan, 2001: Intra-seasonal modulation of convection in the West African monsoon. Geophys. Res. Lett., 28, 523-526.

_ - V. Moron, and B. Fontaine, 1996: Sahel droughts and ENSO dynamics. Geophys. Res. Lett., 23, 515-518.

- A. Harzallah, B. Fontaine, and V. Moron, 1998: West African monsoon dynamics and eastern equatorial Atlantic and Pacific SST anomalies (1970-88). J. Climate, 11, 1874-1882.

— S. Trzaska, and I. Poccard, 2001: Summer Sahel-ENSO teleconnection and decadal time scale SST variations. Climate Dyn., 18, 303-320.

Kiladis, G. N., C. D. Thorncroft, and N. M. J. Hall, 2006: Threedimensional structure and dynamics of African easterly waves. Part I: Observations. J. Atmos. Sci., 63, 2212-2230.

Knippertz, P., 2003: Tropical-extratropical interactions causing precipitation in northwest Africa: Statistical analysis and seasonal variations. Mon. Wea. Rev., 131, 3069-3076.

— cipitation in subtropical and tropical West Africa. Quart. J. Roy. Meteor. Soc., 131, 2337-2365.

Lamb, P. J., 1978: Large-scale tropical Atlantic surface circulation patterns associated with Subsaharan weather anomalies. Tellus, 30A, 240-251.

Laurent, H., N. D'Amato, and T. Lebel, 1998: How important is the contribution of the mesoscale convective complexes to the Sahelian rainfall? Phys. Chem. Earth, 23, 629-633.

Lavaysse, C., A. Diedhiou, H. Laurent, and T. Lebel, 2006: African easterly waves and convective activity in wet and dry sequences of the West African monsoon. Climate Dyn., 27, 319-332.

Lebel, T., A. Diedhiou, and H. Laurent, 2003: Seasonal cycle and interannual variability of the Sahelian rainfall at hydrological scales. J. Geophys. Res., 108, 8389, doi:10.1029/ 2001JD001580.

Louvet, S., B. Fontaine, and P. Roucou, 2003: Active phases and pauses during the installation of the West African monsoon through 5-day CMAP rainfall data (1979-2001). Geophys. Res. Lett., 30, 2271, doi:10.1029/2003GL018058.

Matthews, A. J., 2004: Intraseasonal variability over tropical Africa during northern summer. J. Climate, 17, 2427-2440.

Michelangeli, P.-A., R. Vautard, and B. Legras, 1995: Weather regimes: Recurrence and quasi stationarity. J. Atmos. Sci., 52, 1237-1256.

Mo, K., and M. Ghil, 1988: Cluster analysis of multiple planetary flow regimes. J. Geophys. Res., 93, $10927-10952$.

Molteni, F., S. Tibaldi, and T. N. Palmer, 1990: Regimes in the wintertime circulation over northern extratropics. I: Observational evidence. Quart. J. Roy. Meteor. Soc., 116, 31-67.

Moron, V., 1994: Guinean and Sahelian rainfall anomaly indices at annual and monthly scales (1933-1990). Int. J. Climatol., 14, 325-341.

_ 2005: Skill of Sahelian rainfall index in two atmospheric general circulation models ensemble forced by prescribed sea surface temperatures. CLIVAR Exchanges, No. 33, International CLIVAR Project Office, Southampton, United Kingdom, 14-19.

_ , A. Navarra, M. N. Ward, and E. Roeckner, 1998: Skill and reproducibility of seasonal rainfall patterns in the tropics in ECHAM-4 GCM simulations with prescribed SST. Climate Dyn., 14, 83-100.

- M. N. Ward, and A. Navarra, 2001: Observed and SSTforced seasonal rainfall variability across tropical America. Int. J. Climatol., 21, 1467-1501.

_ N. Philippon, and B. Fontaine, 2003: Skill of Sahel rainfall variability in four atmospheric GCMs forced by prescribed SST. Geophys. Res. Lett., 30, 2221, doi:10.1029/ 2003 GL018006.

- - — and - 2004: Simulation of West African monsoon circulation in four atmospheric general circulation models forced by prescribed sea surface temperature. J. Geophys. Res., 109, D24105, doi:10.1029/2004JD004760.

—, A. W. Robertson, and M. N. Ward, 2006: Seasonal predictability and spatial coherence of rainfall characteristics in the tropical setting of Senegal. Mon. Wea. Rev., 134, 3248-3262.

,,--- , and P. Camberlin, 2007: Spatial coherence of tropical rainfall at regional scale. J. Climate, 20, 5244-5263.

,,$-- \ldots$, and O. Ndiaye, 2008: Weather types and rainfall in Senegal. Part II: Downscaling of GCM simulations. J. Climate, 21, 288-307.

Nicholson, S. E., 1979: Revised rainfall series for the West African subtropics. Mon. Wea. Rev., 107, 620-623.

Paeth, H., and P. Friederichs, 2004: Seasonality and time scales in the relationship between global SST and African rainfall. Climate Dyn., 23, 815-837.

Plaut, G., and E. Simonnet, 2001: Large-scale circulation classification, weather regimes, and local climate over France, the Alps and western Europe. Climate Res., 17, 303-324.

Rasmusson, E. M., and T. H. Carpenter, 1982: Variations in tropical sea surface temperature and surface wind fields associated with the Southern Oscillation/El Niño. Mon. Wea. Rev., 110, 354-384.

Robertson, A. W., and M. Ghil, 1999: Large-scale weather regimes and local climate over the western United States. $J$. Climate, 12, 1796-1813. 
- , and C. R. Mechoso, 2003: Circulation regimes and lowfrequency oscillations in the South Pacific sector. Mon. Wea. Rev., 131, 1566-1576.

—, S. Kirshner, P. Smyth, S. P. Charles, and B. C. Bates, 2006: Subseasonal-to-interdecadal variability of the Australian monsoon over North Queensland. Quart. J. Roy. Meteor. Soc., 132, 519-542.

Rowell, D. P., 2001: Teleconnections between the tropical Pacific and the Sahel. Quart. J. Roy. Meteor. Soc., 127, 1683-1706.

_ C. C. K. Folland, K. Maskell, and M. N. Ward, 1995: Variability of summer rainfall over tropical North Africa (1906-92): Observations and modelling. Quart. J. Roy. Meteor. Soc., 121, 669-704.

Santos, J. A., J. Corte-Real, and S. M. Leite, 2005: Weather regimes and their connection to the winter rainfall in Portugal. Int. J. Climatol., 25, 33-50.

Simmons, A. J., and J. K. Gibson, 2000: The ERA-40 project plan. ERA-40 Project Report Series 1, ECMWF, Reading, United Kingdom, 63 pp.

Sperber, K. R., and T. N. Palmer, 1996: Interannual tropical rainfall variability in general circulation model simulations associated with the Atmospheric Model Intercomparison Project. J. Climate, 9, 2727-2750.

Sultan, B., and S. Janicot, 2000: Abrupt shift of the ITCZ over West Africa and intra-seasonal variability. Geophys. Res. Lett., 27, 3353-3356.
- $\longrightarrow$, and A. Diedhiou, 2003: The West African monsoon dynamics. Part I: Documentation of intraseasonal variability. J. Climate, 16, 3389-3406.

Taleb, E. H., and L. M. Druyan, 2003: Relationships between rainfall and West African wave disturbances in station observations. Int. J. Climatol., 23, 305-313.

Thorncroft, C. D., and B. J. Hoskins, 1994: An idealized study of African easterly waves. I: A linear view. Quart. J. Roy. Meteor. Soc., 120, 953-982.

_ , and D. P. Rowell, 1998: Interannual variability of African wave activity in a general circulation model. Int. J. Climatol., 18, 1305-1323.

Trzaska, S., V. Moron, and B. Fontaine, 1996: Global atmospheric response to specific linear combinations of the main SST modes. Part I: Numerical experiments and preliminary results. Ann. Geophys., 14, 1066-1077.

Vautard, R., K. C. Mo, and M. Ghil, 1990: Statistical significance test for transition matrices of atmospheric Markov chains. $J$. Atmos. Sci., 47, 1926-1931.

Ward, M. N., 1998: Diagnosis and short-lead time prediction of summer rainfall in tropical North Africa at interannual and multidecadal timescales. J. Climate, 11, 3167-3191.

— ability in ensemble GCM simulations: Examples over Europe and the tropical Pacific. J. Climate, 10, 2210-2220. 